\title{
Ambient noise Rayleigh wave tomography across the Madagascar island
}

\author{
N. I. Adimah ${ }^{1,2}$ and S. Padhy ${ }^{1,2}$ \\ ${ }^{1}$ Seismological Observatory, National Geophysical Research Institute (Council of Scientific and Industrial Research), Uppal Road, Hyderabad-500007, \\ India.E-mail:spadhy@ngri.res.in \\ ${ }^{2}$ Academy of Scientific and Innovative Research (AcSIR), AcSIR Headquarters CSIR-HRDC Campus, Postal Staff College Area, Sector 19, Kamla Nehru \\ Nagar, Ghaziabad-201002, India
}

Accepted 2019 November 28. Received 2019 November 20; in original form 2019 July 16

\begin{abstract}
S UMMAR Y
The unusual complex lithospheric structure of Madagascar is a product of a number of important geological events, including: the Pan-African Orogeny, episodes of Late Cenozoic intraplate volcanism and several phases of deformation and metamorphism. Despite this rich history, its detailed crustal structure remains largely underexplored. Here, we take advantage of the recently obtained data set of the RHUM-RUM (Réunion Hotspot and Upper MantleRéunions Unterer Mantel) seismological experiment, in addition to previously available data sets to generate the first Rayleigh wave group velocity maps across the entire island at periods between 5 and $30 \mathrm{~s}$ using the ambient noise tomography technique. Prior to preliminary data preparation, data from Ocean Bottom Seismometers are cleaned of compliance and tilt noise. Cross-correlating noise records yielded over 1900 Rayleigh wave cross-correlation functions from which group velocities were measured to perform surface wave tomography. Dispersion curves extracted from group velocity tomographic maps are inverted to compute a 3-D shear velocity model of the region. Our velocity maps have shown relative improvement in imaging the three sedimentary basins in the western third of the island compared to those of previous studies. The Morondava basin southwest of the island is the broadest and contains the thickest sedimentary rocks while the Antsirinana basin at the northern tip is narrowest and thinnest. The lithosphere beneath the island is characterized by a heterogeneous crust which appears thickest at the centre but thins away towards the margins. A combined effect of uneven erosion of the crust and rifting accommodates our observations along the east coast. Average 1-D shear velocity models in six different tectonic units, support the causes of low velocity zones observed in the west coast of the island and reveal an intermediate-to-felsic Precambrian upper and middle crust consistent with findings of previous seismic studies. Our findings, especially at short periods provide new constraints on shallow crustal structure of the main island region.
\end{abstract}

Key words: Seismic tomography; Africa; Crustal structure; Surface waves and free oscillations; Seismic noise.

\section{INTRODUCTION}

Madagascar is a huge island sitting on the Indian ocean, off the eastern coast of Africa. The Neoproterozoic Pan-African Orogeny gave birth to the Malagasy platform which was later reconstructed by a number of extensional events that led to continental-breakup from Africa and India in the Jurassic and during the Cretaceous, respectively (Coffin \& Rabinowitz 1988; Collins 2006. It also witnessed several episodes of magmatism around the northern and central parts during the Cretaceous and Cenozoic (Besairie 1973; Emerick \& Duncan 1982; Nougier et al. 1986; Tucker \& Conrad 2008).
Madagascar, like several regions associated with the African Plate, has an unusual complex geological structure shaped by a rich history of tectonic and volcanic activities that span over 2.5 billion years of Earth's history. Despite this rich history that preserves a long geological record, the Madagascar plate has received little attention in terms of seismological studies. Prior to 2012 and the recent seismological experiments like the MAdagascar, COmores and MOzambique (MACOMO, Wysession et al. 2011) and the Seismological Signatures in the Lithosphere/Asthenosphere system of Southern Madagascar (SELASOMA, Tilmann et al. 2012) seismic experiments, there were only four permanent broad-band seismometers on the island and as a result there was no island-wide 
seismological study of the region. Its crustal structure was constrained primarily from magnetic and gravity measurements (e.g. Fourno \& Roussel 1994; Rakotondraompiana et al. 1999; Tedla et al. 2011; Tugume et al. 2013). However, in the recent past, the lithospheric and upper-mantle velocity structure of the Madagascar platform and neighbouring regions have been moderately investigated using various seismic tomographic techniques (e.g. Barruol \& Fontaine 2013; Rindraharisaona et al. 2013; Reiss et al. 2016; Andriampenomanana et al. 2017; Mazzullo et al. 2017; Rindraharisaona et al. 2017). All but one of these studies (Paul \& Eakin 2017 ) have generally alluded to a thin crust ( $\sim 13-25 \mathrm{~km})$ along the eastern and western boundaries of the island and a thick crust ( $\sim 32-45 \mathrm{~km}$ ) beneath the centre. Paul \& Eakin (2017) in a receiver function analysis using two permanent seismic stations in Madagascar, obtained a thinner crust $(\sim 39 \mathrm{~km})$ at the centre and a thicker crust $(\sim 44 \mathrm{~km})$ at the eastern coast. Pratt et al. (2017) tested the hypothesis on the origin of the Late Cenozoic alkaline intraplate volcanism in the central, northern and southwestern parts of Madagascar using surface wave tomography. They found three velocity anomalies that appear distinct at depth $<100 \mathrm{~km}$ and correlate well with Madagascar's intraplate volcanisms. This is suggestive that possible connections between these zones lie at greater depth and supports the idea of a possible upwelling asthenosphere beneath the island. Andriampenomanana et al. (2017), from joint inversion of receiver functions and Rayleigh-wave phase-velocity measurements, observed a slight thinning of the crust along the eastern margin of Madagascar which they interpreted as a result of crustal uplift and erosion when Madagascar moved over the Marion hotspot and India broke away from it. Amidst this new-found enthusiasm for seismological studies in Madagascar, the number of studies investigating the lithosphere in the region is still limited and most suffer from limitations in geographical extent and/or resolution. The study by Pratt et al. (2017), interrogating the deep sources of intraplate volcanism in Madagascar generated the first and only island-wide 3-D shear velocity model of the region so far. There has been no island-wide seismological study whose focus is on the shallow features.

In addition to previously available data sets, the recently obtained data set of the RHUM-RUM (Barruol et al. 2017) seismological experiment offers us an unprecedented opportunity to image the crust beneath the Madagascar block at a more detailed scale using the method of ambient seismic noise tomography (ANT). ANT is based on the premise that the Green's function (GF) for waves propagating between two receivers can be retrieved from the cross-correlation of long continuous ambient wavefields, as shown by theoretical, experimental and observational studies in acoustics, ultrasonics and seismology (Lobkis \& Weaver 2001; Campillo \& Paul 2003; Malcolm et al. 2004; Shapiro \& Campillo 2004; Snieder 2004; Wapenaar 2004; Weaver \& Lobkis 2004; Roux et al. 2005). This technique, although relatively new, has been widely applied to obtain high resolution 2-D phase and group velocity maps of the crust and uppermost mantle. Its suitability in regions characterized by moderate seismicity like Madagascar (Rindraharisaona et al. 2013) gives it an advantage over the traditional surface wave tomography based on earthquake records. Also, temporal repeatability, a salutary feature of ambient noise measurements allows for a robust and quantitative estimation of measurement uncertainty, unlike in earthquake based analysis. Several high-resolution studies have been carried out at different scales in the past decade (e.g. Shapiro et al. 2005; Yang et al. 2007; Luo et al. 2012; Gaite et al. 2012; Young et al. 2013; Bao et al. 2015; Gilligan et al. 2015; Goutorbe et al. 2015; Taylor et al. 2016; Green et al. 2017; Legendre et al. 2017; Ojo et al. 2017).
The objective of this study is to image the crustal structure beneath the entire Madagascar platform, taking advantage of the extensive data set from both island and ocean bottom seismic stations of the RHUM-RUM and MACOMO experiments which can potentially improve the resolution and fidelity of images obtained, especially within the Cretaceous volcanic formation along the east coast of the study area. Informed by our goal to constrain the crust and possibly the uppermost mantle structure, including the shallow sedimentary structures, we focus on the 5-30 s period band. The group velocity that corresponds to propagation of wave group energy is more sensitive to phenomena like scattering, multipathing, wave conversions, etc., ubiquitous in heterogeneous crust, thus its analyses tightly constrain the crustal structure including basins more prominently at short period end of the 5-30 s band studied here. Group velocities are related to partial derivative of phase velocities, hence small perturbations in phase velocity lead to large variations in group velocity (Yu \& Mitchell 1979). The maximum amplitudes of group velocity partials (i.e. depth sensitivity kernels of group velocity with respect to shear wave velocity) are greater than those of the phase velocity (Guidarelli et al. 2017). Also, the depths of maximum sensitivity of group velocity are sharply limited to a narrow range in depth in the shallow heterogeneous crust compared to those of phase velocity in the short periods. High quality Rayleigh wave group-velocities are measured and then inverted to obtain 2-D group-velocity and resolution maps. A 3-D shear velocity model is compiled from 1-D shear velocity structures obtained at each grid point. To uniquely characterize different geologic and tectonic blocks in the region, we inverted for the average 1-D shear velocity structure of six geologic and tectonic units within the island. Finally, we correlate our results with major geological units and compare them with previous findings over the area.

\section{GEOLOGICAL BACKGROUND}

The overall geology of Madagascar is generally divided into two structural zones: the sedimentary basin covering the western third of the island and the Precambrian shield occupying the remaining two-thirds (Fig. 1). The sedimentary basin of the island is covered by depositional sequences equivalent to the Karroo Supergroup of continental Africa (Schlüter 2006). Although the deposits form a continuous belt, they are generally subdivided into the Morondava Basin along the western coast and the Antsiranana Basin on the northwestern coast of the island. They were formed during the rifting away of Madagascar from Africa along the Davie Ridge, which started in the Late Palaeaozoic and was complete by the Late Jurassic and Early Cretaceous (Rabinowitz et al. 1983). The deposition of sediments progressed from south to north and from west to east, accompanying the northward progression of the opening of the basins (Besairie 1971; Piqué 1999a). These sedimentary rocks range in age from the Carboniferous to recent. On the other hand, the remaining two-thirds of the island, on the eastern side, consist pre-dominantly of Precambrian and Cambrian rocks (e.g. Nicollet 1990; de Wit 2003). The Antongil-Masora craton, the Antananarivo, Anosyen-Androyen, Ikalamavony, Vohibory and Bemarivo terranes make up the major units of the Precambrian basement. The Antogil-Masora craton located in two patches along the east coast of Madagascar contains the oldest $\operatorname{rocks}(\sim 3.3 \mathrm{Ga})$ in Madagascar (Tucker et al. 2011). The Antananarivo terrane, made up mainly of Neoarchean $(\sim 2.5 \mathrm{Ga})$ orthogneisses and paragneisses (Tucker et al. 2011, 2012), dominates the central part of the island and covers majority of the Precambrian shield. Southernmost 


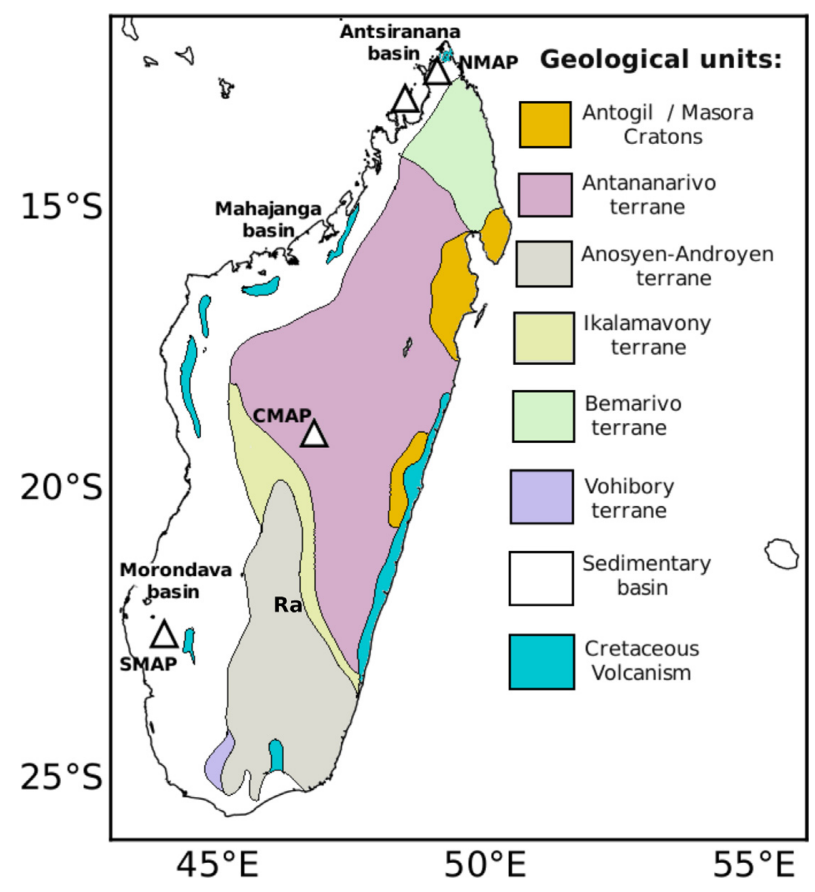

Figure 1. A simplified seismotectonic map of Madagascar island. The white triangles indicate regions of recent alkaline intraplate volcanism. NMAP, Northern Madagascar Alkaline Province; SMAP, Southwestern Madagascar Alkaline Province; Ra, Ranotsara shear zone.

of the Precambrian shield is the Anosyen-Androyen terrane while the younger Ikalamavony terrane with a narrow NNW-SSE striking zone demarcates it from Antananarivo terrane. The Bemarivo terrane of northern Madagascar comprises Neoproterozoic ( $\sim 758$ $708 \mathrm{Ma}$ ) intrusive granitic and volcanosedimentary rocks (Thomas et al. 2009; Tucker et al. 2012). West of the Anosyen-Androyen terrane is an oceanic terrane of early Neoproterozoic age: the Vohibory terrane and is composed of intercalations of metabasalts, acidic volcanic rocks, and chemical metasedimentary rocks (GAF-BGR 2008; Jöns \& Schenk 2008). The eastern rifted margin of Madagascar island, stretching up to a length of $\sim 1500 \mathrm{~km}$, is characterized by widespread basalts and rhyolites which erupted during the Late Cretaceous (Storey et al. 1995). These eruptions have been tied to the passage of Madagascar-India-Seychelles over the Marion hot spot and subsequent rifting which led to the separation of Madagascar from India. Unlike the west coast containing sedimentary basins, the geometry of the rifting along the eastern margin of the island precluded the formation of sedimentary basins in the region. Finally, the passive continental margin adjacent to the east coast of Madagascar island is dominated by several 84-92 Ma mafic-ultra mafic complexes (Torsvik et al. 1998).

\section{DATA AND METHOD OF ANALYSIS}

The data used here comprise approximately $1 \mathrm{yr}$ of continuous Zcomponent (land and island stations) and three component $[\mathrm{Z}, \mathrm{N}, \mathrm{E}$; Ocean Bottom Seismometers (OBS)] ambient seismic noise records publicly available from IRIS (Incorporated Research Institutions for Seismology) data management centre, RESIF (French seismologic and geodetic network), Institut De Physique Du Globe De Paris (IPGP) and GEOFON Global Seismic Network. A fourth component (Pressure record) was also collected for OBS stations. These data were recorded by 27 temporary broad-band seismic stations of the MACOMO experiment (Wysession et al. 2011), 4 permanent broad-band stations and 32 (5 continental, 11 island and 16 OBS) temporary stations of the RHUM-RUM experiment (Fig. 2). The MACOMO experiment installed 36 broad-band instruments (17 Streckeisen STS-2s, 9 Guralp CMG-3Ts, 10 Trillium 120PAs) at 6 locations within Mozambique and 26 locations within Madagascar. The experiment which started in October, 2011 came to completion in August, 2013 and hence all instruments were removed. The RHUM-RUM project deployed 57 broad-band OBS to the east and south of Madagascar for $1 \mathrm{yr}$. Each was equipped with either a Nanometrics Trillium 240 or Guralp CMG-40T-OBS sensor, and colocated with a pressure sensor. This was augmented by land deployments in the Iles Eparses in the Mozambique Channel, in Madagascar and several other islands surrounding Madagascar. See Barruol et al. (2017) for more details. The four permanent stations used in this study include: FOMA (G GEOSCOPE, 2008-present), ABPO (II GSN, 2007-present), VOI and SBV [GE GEOFON, 2009-present; GEOFON Data Center (1993), Fig. 2]. This section recounts our data pre-processing and dispersion curve measurement approach, inversion for 2-D Rayleigh wave group-velocity tomographic maps, resolution analysis using three schemes and finally, inversion for a 3-D shear wave velocity model of the study region.

\subsection{Signal pre-processing and cross-correlations}

OBS and island stations suffer from locally generated noise that can obscure the observation of the long-distance coherent wavefield which is the basis of ANT (Lin et al. 2006). Even though ambient noise sources are relatively well distributed in time and space across the Earth's oceans, their direct effect on a lone OBS is responsible for generating incoherent signals especially at longer periods ( $>25 \mathrm{~s}$ ) which are unfavourable to the retrieval of noise correlations (Bowden et al. 2016). As a result, and unlike traditional land-based seismographs, OBS data contain significantly higher amount of noise emanating from their underwater environments and as such require special pre-processing before their use in ambient noise studies. These incoherent long period signals are probably caused by tilting under fluid flow (tilt noise) and seafloor deformation under surface gravity waves (compliance noise) which can raise deep seafloor vertical component noise by 35-40 dB and 5$15 \mathrm{~dB}$, respectively (Webb \& Crawford 1999; Crawford et al. 2006). Thankfully, the horizontal component and seafloor pressure gauge data also record these disruptive signals. Amongst others, Crawford et al. (2006) has demonstrated the ability to use these records to correct vertical component OBS data for tilt and compliance noise.

A physical examination of our signals reveals a relatively good coherence between the pressure and vertical component measurements (Fig. 3), indicating that compliance noise may be the dominant contaminant of the vertical signal. Nevertheless, we have proceeded to remove both tilt and compliance noise from the vertical OBS records. We followed approximately the method presented by Bell et al. (2015), which is an extension of the work of Crawford \& Webb (2000). The method involves calculating a transfer function of the vertical component, for non-vertical components. The predicted tilt and compliance noise derived from the transfer functions which represent the coherence between the non-vertical components and the vertical component are subtracted from the vertical component giving a cleaned signal. To ensure traces of the tilt noise are not corrected twice, we proceed as follows: (1) Calculate and apply transfer function from one horizontal component to all other components, (2) Calculate and apply transfer function from the second 


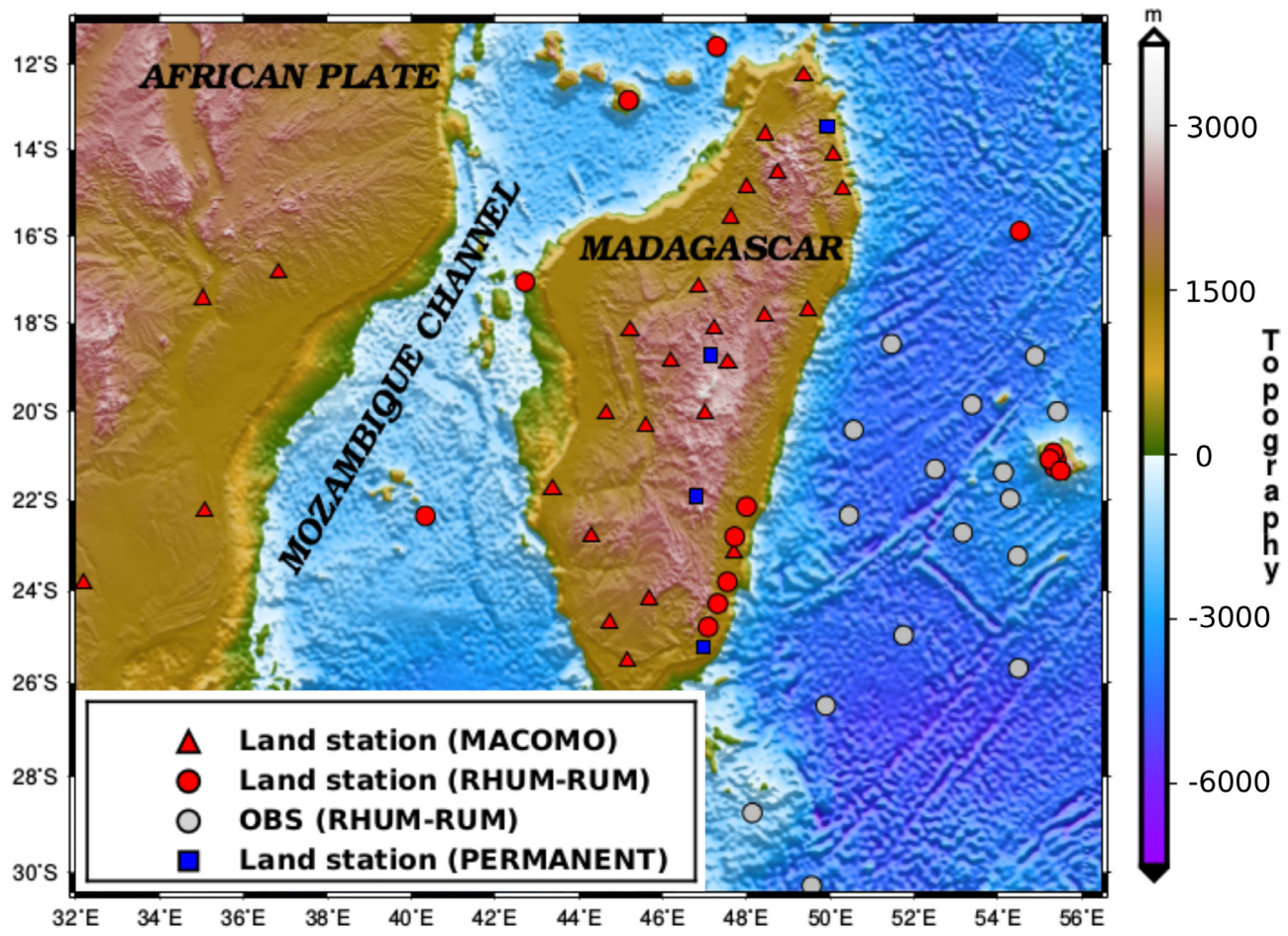

Figure 2. Bathymetry/Topography map of the study area showing the seismic stations used in this study. Please, see Table S1 in Supplementary information for a detailed list.

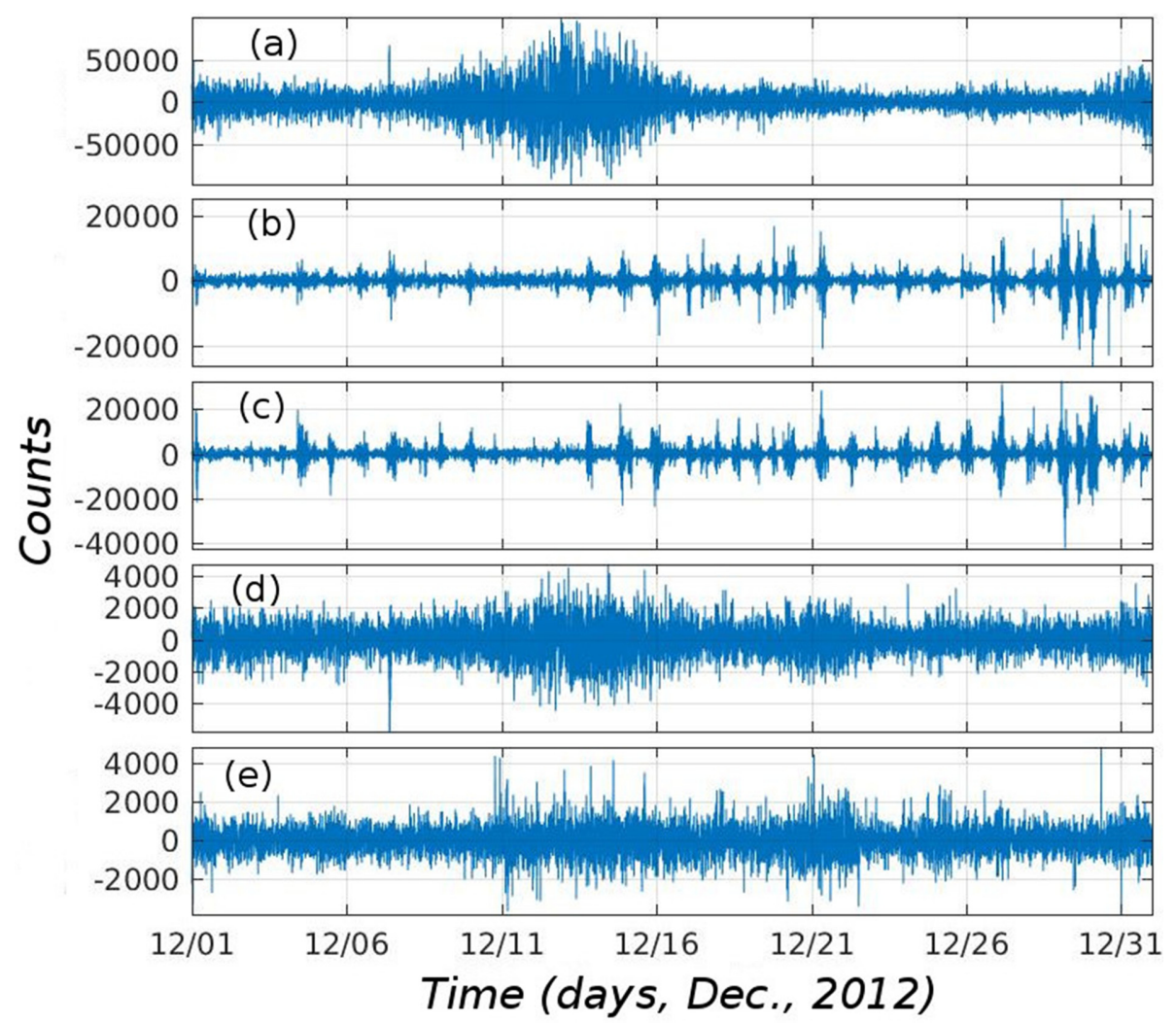

Figure 3. A plot of approximately one month (December, 2012) long raw and corrected signals from the OBS station RR03 of the RHUM-RUM network. From (a) to (e): raw pressure record, raw N-S component, raw E-W component, raw Z component and Z component after removing coherent pressure and horizontal signals. Note, a relatively strong coherence between the pressure and vertical component records shown in (a) and (d), respectively. 
horizontal component to the pressure and vertical components and (3) Finally, transfer function from the pressure record is applied to the vertical component (Fig. 3).

Although this method generally applies to longer-period ( $\sim 15$ s) signals, quite similar to Bowden et al. (2016), we have observed a relative improvement in the short to intermediate (5$20 \mathrm{~s}$ ) period measurements compared with the longer period ( $20 \mathrm{~s}$ ) measurements after its application (see section 5 in Supplementary information). In general, the noise levels in the vertical component data were fairly suppressed (Figs 3, S7 and S8) and crosscorrelations obtained from them were of relatively higher signalto-noise ratio (SNR). We observed variation in reduction of noise levels of the denoised vertical component for data recorded by different stations and for different times (months) (see Figs S7 and S8, section 5 of the Supplementary information).

After correcting the vertical OBS data for tilt and compliance noise, they are subjected to further pre-processing alongside data from continental and island stations. For this segment of preprocessing, we follow the method described by Bensen et al. (2007). Data for each station are cut into daily records, downsampled to $1 \mathrm{~Hz}$, instrument response is removed, mean and trend are removed and the signal is bandpass filtered between 0.02 and $0.4 \mathrm{~Hz}$. This frequency band is sensitive to the crust and uppermost mantle which is the target of our study. The daily-filtered records are subjected to running-absolute-mean temporal normalization which suppresses earthquake signals, instrumental irregularities and other contaminants that may obscure the noise records. This method of temporal normalization has been shown by Bensen et al. (2007) and several others to provide a substantial improvement in SNR values compared to the widely used one-bit normalization. To extend the band of the ambient noise signal in the correlograms and reduce the effect of a persistent narrow-band $(\sim 0.038 \mathrm{~Hz}$ or $26 \mathrm{~s})$ noise source in the Gulf of Guinea (Shapiro et al. 2006), the signals are whitened. Daily time-series data are further cut into 1-hr segments and crosscorrelated for all possible station pairs. The cross-correlation function $(\mathrm{CCF})$ between data recorded at two stations: $U_{A}(t)$ and $U_{B}(t)$ over time duration, $T$, is given as:

$C_{A B}(\tau)=\int_{0}^{T} U_{A}(t) U_{B}(t+\tau) \mathrm{d} t$

The hourly cross-correlations obtained are stacked with their timereversed cross-correlations to suppress errors in the CCFs due to non-uniform distributions of the noise field. They are then stacked into daily CCFs which are finally stacked into 1-yr-long timeseries to obtain the estimated Green's functions. This process finally yielded a total of 1953 CCFs obtained for 63 broad-band seismic stations (Fig. 4).

As already alluded to, data from OBS and island stations are contaminated by locally generated noise which negatively bias the retrieval of high quality estimated Green's functions. Correcting the OBS data for tilt and compliance noise reduced these incoherent signals in the CCFs and consequently improved the SNR of the CCFs (e.g. Fig. 5). Fig. 5 shows the CCFs between a land station BARY and the OBS RR03 before and after the removal of tilt and compliance noise. The SNR after denoising is fairly improved across most period bands.

\subsection{Dispersion curves}

The difference in elevation between station pairs involving OBS and land stations is uncharacteristically large, reaching up to $\sim 7 \mathrm{~km}$ in

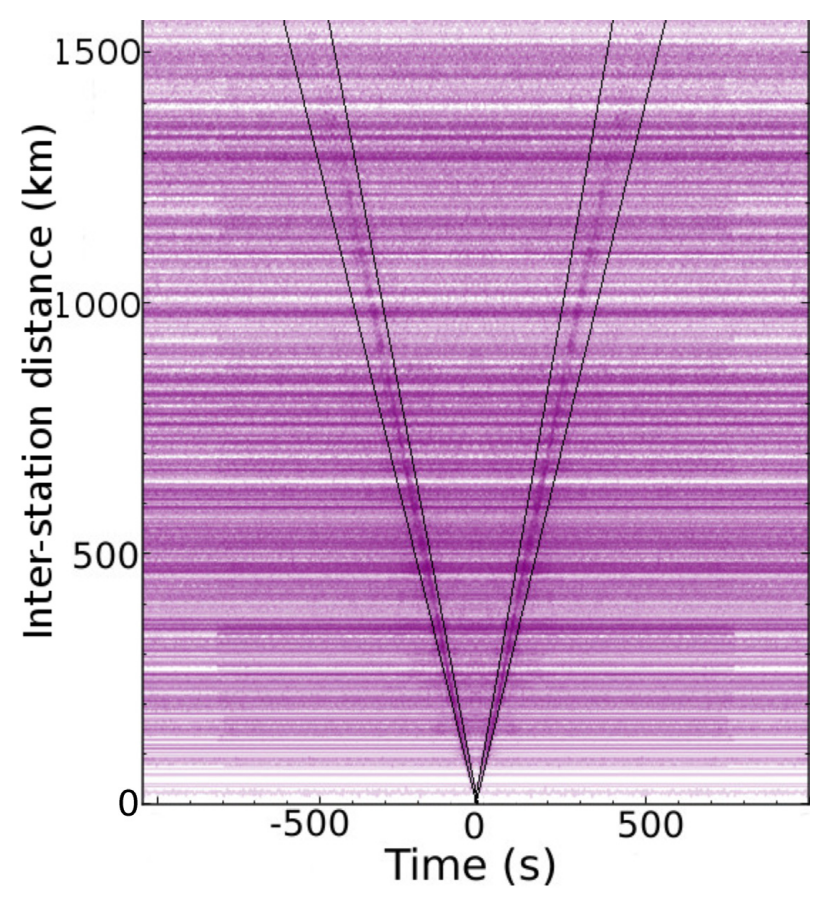

Figure 4. Example of band-passed (2.5-50 s) cross-correlations obtained from $1 \mathrm{yr}$ of data plotted as a function of distance. The solid lines with apparent velocities of 2.0 and $4.0 \mathrm{~km} \mathrm{~s}^{-1}$ are shown.

some cases. It is likely that more complicated effects such as scattering, multipathing, reflections and conversions due to the topographic change are the reasons why the elevation difference between the continent and the seafloor affects the inversion.

Using the stacked CCFs as input, the Rayleigh-wave groupvelocity dispersions are measured using frequency-time analysis (FTAN). This technique is based on the application of narrow bandpass Gaussian filters to the CCFs. The two-step FTAN procedure given by Bensen et al. (2007) and Levshin \& Ritzwoller (2001) is followed here. First, the CCFs are subjected to a set of narrow bandpass Gaussian filters with centre frequencies $\omega_{0}$. The peak amplitude of the filtered signal corresponds to the traveltime of the Rayleigh wave which gives the group velocity $v_{g}$ at the instantaneous period, T, of the filtered signal [raw dispersion curve, $v_{g}(T)$ ]. Using the phase-matched or antidispersion filter, the obtained FTAN image (raw FTAN) is further improved by applying a correction in phase to the phase of the analytical signal, as described in detail in Goutorbe et al. (2015). By repeating the first step to the phasecorrected CCFs, we obtain clean FTAN image (Fig. 6).

To ensure that only reliable dispersion measurements are selected for further analysis, we enforced a number of quality control measures. Firstly, we enforce the maximum cut-off period criterion of Bensen et al. (2007), which is given by $\tau_{\max }<\delta / 3 c$, where $\delta$ is the interstation distance in $\mathrm{km}$ and $\mathrm{c}$ is the group speed in $\mathrm{km} \mathrm{s}^{-1}$. Because most interstation distances in this study are relatively large, very few dispersion measurements were rejected based on this criterion. Secondly, a SNR $\geq 7$ was imposed. Here, the SNR is defined as the ratio of the maximum absolute value in the signal window to the standard deviation in the noise window. We define the signal as the portion of the data windowed between arrival times corresponding to velocities between 2 and $4.5 \mathrm{~km} \mathrm{~s}^{-1}$. The noise window has a width of $500 \mathrm{~s}$ beginning $500 \mathrm{~s}$ from the end of the signal window. This criterion accounts for majority of the rejected measurements 
(a) BARY - RR03 (RAW)

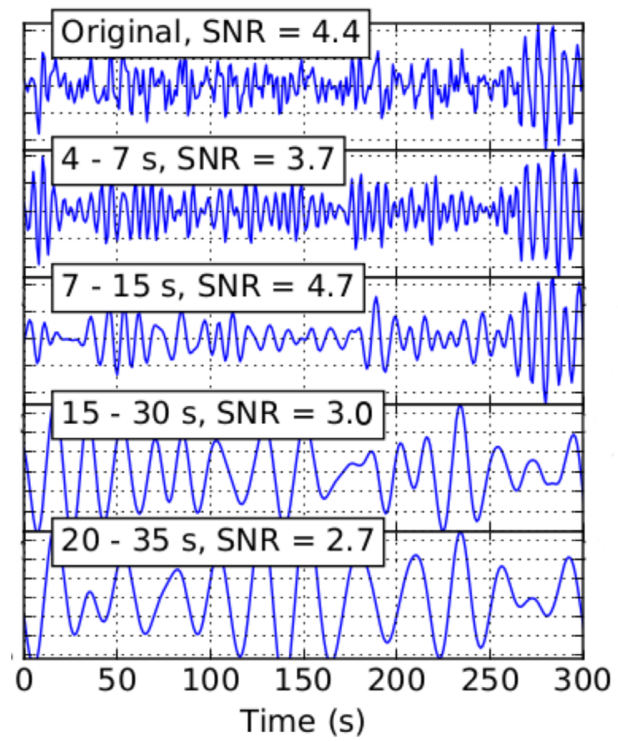

(b) BARY - RR03 (DENOISED)

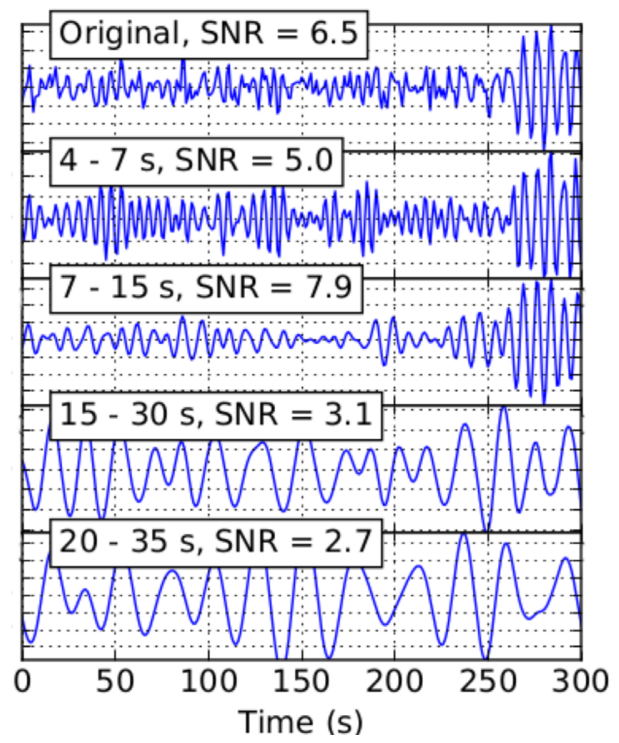

Figure 5. Z-component noise cross-correlations in several period bands for seismic stations BARY (land) and RR03 (OBS). (a) Cross-correlation computed without correcting for tilt and compliance noise in Z-component of RR03. (b) Similar to (a), but after the removal of tilt and compliance noise from RR03.

(especially those involving island and OBS stations). The SNR criterion was, however, relaxed to $\geq 4.5$ in a few cases involving OBS stations.

Temporal repeatability is also a very useful way to estimate reliability of dispersion measurements. Sources of ambient noise change seasonally and provide different conditions for the measurement so that the repeatability of a measurement is a significant indicator of reliability. To this end, we assessed the seasonal variability of the dispersion curves by performing FTAN on 3 months (Sept-OctNov, Oct-Nov-Dec, ..., Jul-Aug-Sept) cross-correlations (Fig. 6). Majority of the CCFs exhibited low seasonal variability. Finally, we visually inspected each CCF to further discard bad measurements. Examples of CCFs, FTAN analysis and seasonal variability are shown in Fig. 6. Dispersion curves obtained from cross-correlating data from stations within the Precambrian basement show relatively high velocities and small variations with period, suggesting the presence of thick crust and lack of an overlying sedimentary layer along the propagation paths. Those curves traversing the sedimentary basin show very low velocities at short periods, revealing the existence of sediments (top panels of Fig. S1).

\subsection{Group velocity tomographic inversion}

To invert obtained dispersion measurements for 2-D Rayleigh wave group velocity maps at a set of discrete periods, we employ the ray theoretic inversion scheme of Barmin et al. (2001). A brief overview of the inversion method is presented here. This method assumes the seismic surface waves as rays sampling an infinitesimal zone along the great circle linking sources and receivers (station pairs in this case). The general equation for the underlying linear inverse problem can be expressed at any given period $T$ :

$d=G m$

$d$ is a vector of traveltime residuals relative to a reference model (defined as the mean slowness implied by all observed traveltimes) between pairs of stations (deduced from the measured group velocities and predicted traveltime at period, $T$ ), $m$ is a vector of slowness perturbations along the nodes of a regular grid, and $G$ is the forward matrix that computes the traveltime along the wave paths on a reference map. The modeled slowness is discretized along a regular $0.5^{\circ} \times 0.5^{\circ}$ grid .

To estimate $m$, the following penalty function consisting of three terms is minimized:

$(G m-d)^{T} C^{-1}(G m-d)+\alpha^{2}\|F(m)\|^{2}+\beta^{2}\|H(m)\|^{2}$.

The first term of the penalty function represents data misfit where $\mathrm{C}$ is the a priori covariance matrix of observational errors, which is a diagonal matrix containing the variance of errors on the observed traveltimes. To construct this matrix, we follow strictly the method defined by Goutorbe et al. (2015). $\alpha$ and $\beta$ are the strengths of the spatial smoothing and norm penalizing terms, respectively.

The second term is the spatial smoothing condition such that:

$F_{\mathrm{ij}}= \begin{cases}1, & \text { if } i=j, \\ -S\left(r_{i}, r_{j}\right), & \text { if } i \neq j,\end{cases}$

where $\sigma$ is the spatial smoothing width and $S\left(r_{i}, r_{j}\right)$ is the smoothing kernel given as:

$S\left(r_{i}, r_{j}\right) \propto \exp \left(-\frac{\left\|r_{i}-r_{j}\right\|^{2}}{2 \sigma^{2}}\right)$,

$\sum_{j \neq i} S\left(r_{i}, r_{j}\right)=1 \quad \forall i$

with $r_{i}$ the position of the $i$ th grid node.

The final term in the penalty function penalizes the weighted norm of the model, with a weighting function decaying exponentially with path density, as defined below, approaches zero and unity in areas of high and low path coverage, respectively (Barmin et al. 2001):

$H_{i j}=\exp \left(-\lambda \rho_{i}\right) \delta_{i j}$,

where $\lambda$ is the user-defined constant, chosen as $0.3, \delta_{i j}$ is the Kronecker delta function and $\rho_{i}$ is the number of paths that cross the $0.5^{\circ} \times 0.5^{\circ}$ cell centred on the $i$ th node of the grid. Its effect is to merge the estimated model smoothly and continuously into the reference one in regions of poor data coverage. 
ANTS-VOI (Distance $=788 \mathrm{~km}, \mathbf{n b}$ of days $=\mathbf{3 5 1}$ )
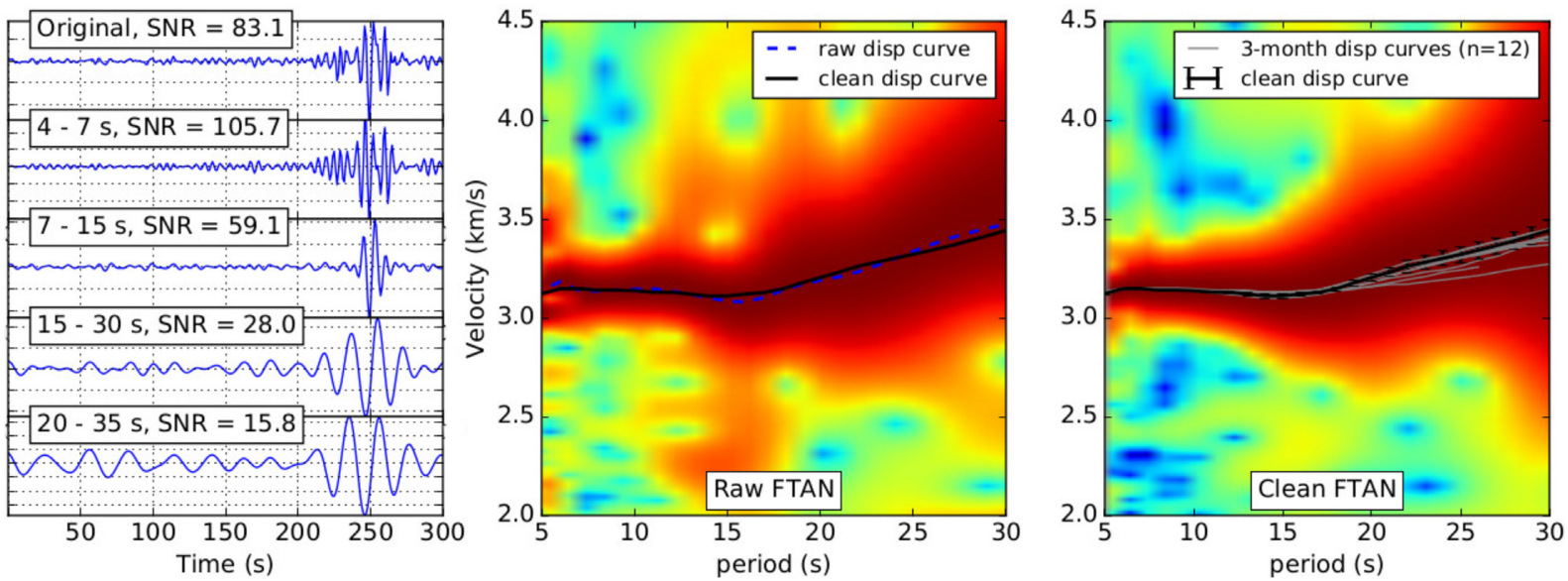

BERG-RR29 (Distance $=\mathbf{1 1 2 4} \mathbf{~ k m}, \mathbf{n b}$ of days $=\mathbf{3 2 0}$ )
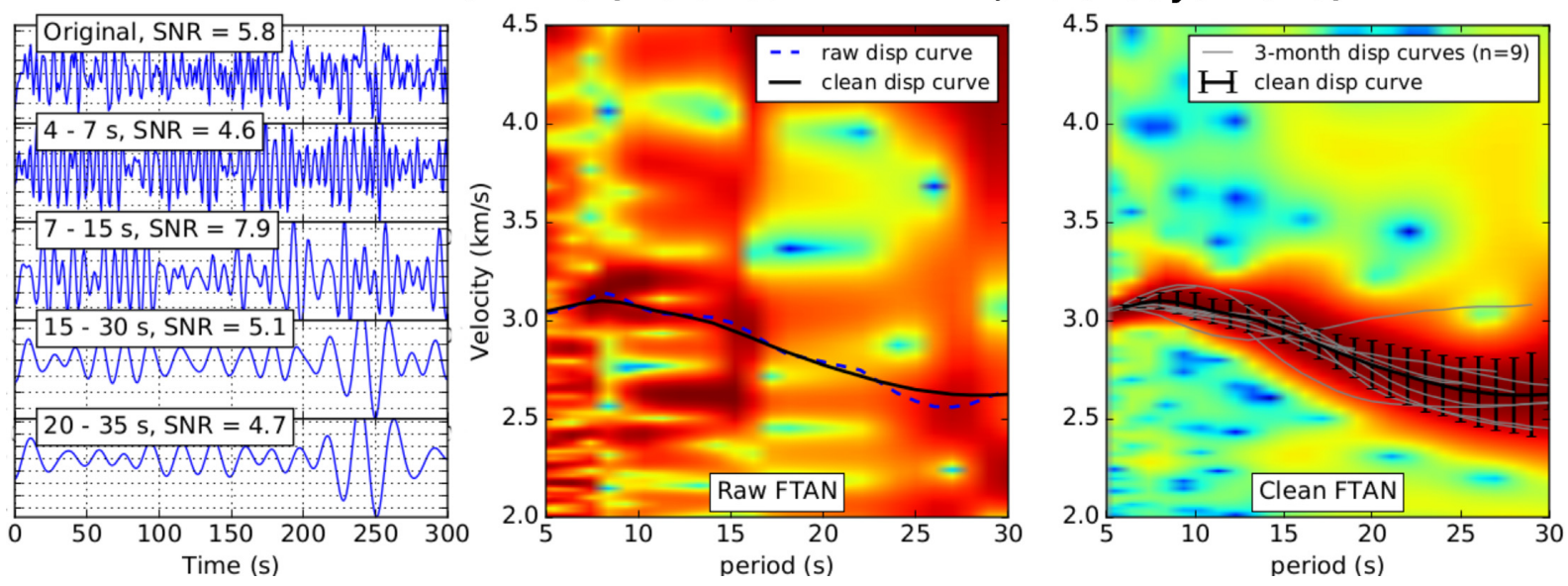

Figure 6. Two examples of cross-correlations and frequency-time analysis (FTAN) involving seafloor- and land-based seismic broad-band stations. From left to right in top and bottom panels: original and bandpass filtered symmetrical-component cross-correlations, corresponding raw FTAN image and clean FTAN image displaying group velocity dispersion curves computed from $1 \mathrm{yr}$ and 3 months CCFs. Note, cross-correlations involving OBS stations (bottom panel) generally have lower SNR and higher seasonal/temporal variability.

The two conditions required for constructing reliable tomographic images are initial outlier rejection (data cleaning) and a cautious choice of the user-defined regularization parameters $(\alpha, \beta$ and $\sigma$ ) appropriate for a given path coverage (Barmin et al. 2001). As recommended by Barmin et al. (2001), we have employed the two-part inversion procedure to clean the data of outliers with high traveltime residuals that may have passed the selection criteria for obtaining the final group velocity dispersion maps at different time periods. The first part of the inversion is carried out with a large value given to the spatial smoothing parameter $(\alpha=3000)$ to obtain a highly smoothed map. Data for which residuals are larger than three times the standard deviation of the residuals are discarded. Then a second part inversion is performed with the cleaned data for the values of inversion parameters listed in Table 1 to produce the final maps. A series of tests with different possible combinations of these parameters is done systematically to determine the parameter values for obtaining the final maps that correlate well with principal geological features of the region. The optimal combination of parameters takes care of features like data misfit (good data fit), model resolution (smooth model) and model norm that govern the penalty function, as demonstrated in previous studies (Yang et al. 2007; Gaite et al. 2012) (Further discussion can be found in Section 2
Table 1. Parameters of the inversion.

\begin{tabular}{lc}
\hline Parameters & Value \\
\hline Discretization grid & $0.5^{\circ} \times 0.5^{\circ}$ \\
$\alpha$ Strength of the spatial smoothing term & $(3000,200-300)^{*}$ \\
$\sigma$ Spatial smoothing width & $(50-150) \mathrm{km}$ \\
$\beta$ Strength of the norm penalizing term & $(150-200)$ \\
$\lambda$ Constant used in the weighting function (eq. 7) & 0.3
\end{tabular}

*First and second pass of the inversion, respectively.

of the accompanying Supplementary information). To assess the goodness of fit of our estimated models across all investigated periods, misfit posed as variance reduction delivered by the resulting models relative to the predicted group velocity maps was computed as a function of time period (Fig. S2). Variance reduction is highest ( $>80$ per cent) at short periods $(<15 \mathrm{~s})$ and gradually decrease with period. Overall, it exceeds 70 per cent across all investigated periods except at the longer ( $>25 \mathrm{~s}$ ) periods, indicating an improvement in fit to the measured data by the resulting group velocity maps, especially at short periods.

Although most recent studies have moved towards diffraction tomography using spatially extended finite-frequency sensitivity kernels based on the Born/Rytov approximation (e.g. Ritzwoller et al. 
2002; Yoshizawa \& Kennett 2002; Zhou et al. 2004), the surface wave tomography method employed here uses ray theory to compute the traveltimes of Rayleigh waves. Studies by Ritzwoller et al. (2002) and Sieminski et al. (2004) have shown that both methods recover almost similar structure with nearly identical resolution for periods shorter than $50 \mathrm{~s}$ with dense path coverage, so that the ray theory nearly suffices for this study.

To ascertain the limitations of our computed Rayleigh-wave group velocity maps at discrete periods between 5 and $30 \mathrm{~s}$, we now assess their reliability.

\subsection{Resolution analysis}

To accurately interpret the group velocity maps, estimating their resolution is of great importance. We show first the inter-station paths available for the tomographic inversion at each period considered (Fig. 7, left-hand panel), on which resolution at a given period depends on. Of all four periods investigated, the lowest number of paths (376 paths) was recorded at $30 \mathrm{~s}$ period and the highest ( 824 paths) at $10 \mathrm{~s}$ period (Fig. 8).

At all periods, the central parts of the maps (island area) are well illuminated compared to the margins (especially around the Mozambique channel) which is clearly due to a non-uniform spatial distribution of stations. Comparing with most studies having similar spatial extent, our ray path coverage is relatively higher and would be expected to reliably retrieve the detailed structure beneath the study area, at least of the island. Additionally, we show spatial resolution maps (Fig. 7, middle panel) at each period for which tomographic inversion was carried out. To plot spatial resolution maps, we accessed the resolution matrix obtained from the inversion procedure described, following the method of Barmin et al. (2001). The spatial resolution at short periods $(<20 \mathrm{~s})$ is $<250 \mathrm{~km}$ with an average resolution of $\sim 150 \mathrm{~km}$, particularly at $5-10 \mathrm{~s}$ period range within the central regions of Madagascar consisting of the Antananarivo terrane, the Neoproterozoic Vohibory region, the Anosyen-Androyen terrane and part of the Antogil craton (Fig. 1). The resolution degrades at long period with an average resolution of $\sim 250-300 \mathrm{~km}$ at $30 \mathrm{~s}$, however. At all periods, there is gradual degradation in resolution moving away from the main island towards Mozambique channel to the left and Reunion island to the right due to poorer data coverage.

The well-known checkerboard test was also performed to further scrutinize the tomographic maps qualitatively. A checkerboard model of velocity having alternating sinusoidal anomalies of \pm 10 per cent about a reference background velocity of $3 \mathrm{~km} \mathrm{~s}^{-1}$ was used to generate synthetic data that replaced observed traveltimes in the tomographic inversion. The centres of two neighbour anomalies are around $250 \mathrm{~km}$ apart. The test results (Fig. 7, right-hand panel and Fig. S3) show that checkers are well recovered in majority of Madagascar where the spatial resolution is around $250 \mathrm{~km}$, path density is high and azimuthal coverage is good, across all periods. Smaller anomaly sized checkerboards (e.g. $150 \mathrm{~km}$ and $200 \mathrm{~km}$ ) were recovered at the shorter periods (Fig. S4), corroborating resolution of up to $\sim 150 \mathrm{~km}$ revealed by the spatial resolution test. This consistency among all the three resolution schemes is seen in areas like the Mozambique channel and off the eastern margin of Madagascar towards La Reunion island where spatial resolution is poorer than $\sim 350 \mathrm{~km}$ and path coverage is sparse, revealing the limitations of our group velocity tomographic maps for these parts of the study area (Fig. 9). Thus, we emphasize seismic velocity structure mostly within the main island area and regions in the Indian ocean few kilometres away from the east coast of the island where the average resolution is relatively good $(\sim 150-200 \mathrm{~km})$ at short to mid-period ( $\leq 20 \mathrm{~s}$ ) range.

\subsection{Inversion for shear wave velocity}

To invert for shear velocity structure, the suite of group velocity maps generated at periods 5 to $30 \mathrm{~s}$ with increment of $1 \mathrm{~s}$, are resized to exclude regions poorly constrained (resolution $>280 \mathrm{~km}$ ) like the Mozambique channel and south Indian ocean. This resulted in 464 grid nodes for which dispersion curves are then reconstructed and inverted for the 1-D shear velocity structure using a linearized iterative inversion scheme (surf96 - (Herrmann \& Ammon 2004)). To characterize and distinguish between the major tectonic units and geological features in the study area, we present here examples of the average group velocity dispersion curves in six representative regions within the Madagascar island (see Table 2) and inverted for their corresponding shear velocity structures.

Our parametrization assumed a 1-D layered model composed of $70 \times 1-\mathrm{km}$-thick layers for the upper $70 \mathrm{~km}$, above a half space. The iterative inversion at each grid point was performed using a starting model that consists of a constant gradient shear velocity crust over an AK135 (Kennett et al. 1995) half space upper mantle with crustal parameters defined within the values obtained by previous studies in the area (e.g. Andriampenomanana et al. 2017; Pratt et al. 2017). Several trials using smoothing values in the $0-10$ range were conducted before constraining the smoothness to 0.8 for the inversions. After 40 iterations which were sufficient for the models to converge, we observed a relatively good fit between the synthetic and observed dispersion curves, at least for points within the Madagascar island, as shown in the top panels of Figs 10(a)-(f). The highest mean standard deviation of group-velocity misfit for all periods is $0.012 \mathrm{~km} \mathrm{~s}^{-1}$ with no single measurement deviating more than $0.15 \mathrm{~km} \mathrm{~s}^{-1}$.

The linearized inversion technique is well-known to show dependence on the initial model. Hence, to elucidate the extent of this dependence and non-uniqueness inherent to the inversion, and ultimately determine which features of the crustal structure are tightly constrained, we used a wide range of starting models for the inversion at the six different regions described in Table 2. We used half-space starting models adopted from the AK135 global earth model, constant velocity-gradient crust over a half space, and dual layered upper-lower crust over a half space, similar to those used by Green et al. (2017). The depths in which we achieve good resolution are controlled by the available group-velocity measurements at time periods selected. Final shear velocity models shown in bottom panels of Figs 10(a)-(f) and the mean shear velocity model in Fig. 11(a) are quite consistent for the upper $\sim 23 \mathrm{~km}$, but below this depth the variance of the set of recovered models (Fig. 11b) in most of the regions increased sporadically. This interprets as dependence of the final shear velocities in the lower crust and uppermost mantle on the starting model in contrast to consistent shear velocity structures in the upper- and middle-crust. Although long period Rayleigh wave group dispersions $(\sim 20-30$ s) still show sensitivity to the shear wave structure of the lower crust and uppermost mantle as revealed from their sensitivity kernels to be discussed later, the resulting 1-D shear wave models beyond $23 \mathrm{~km}$ depth are relatively inconsistent and may have been biased by the initial models. However, based on extensive data analysis, we found that it is mostly the use of OBS data, especially at long periods $(\sim 25-30 \mathrm{~s})$ that degrade the quality of waveforms by markedly reducing the SNR (Fig. 7) and by extension the raypath coverage (Fig. 8) than the 

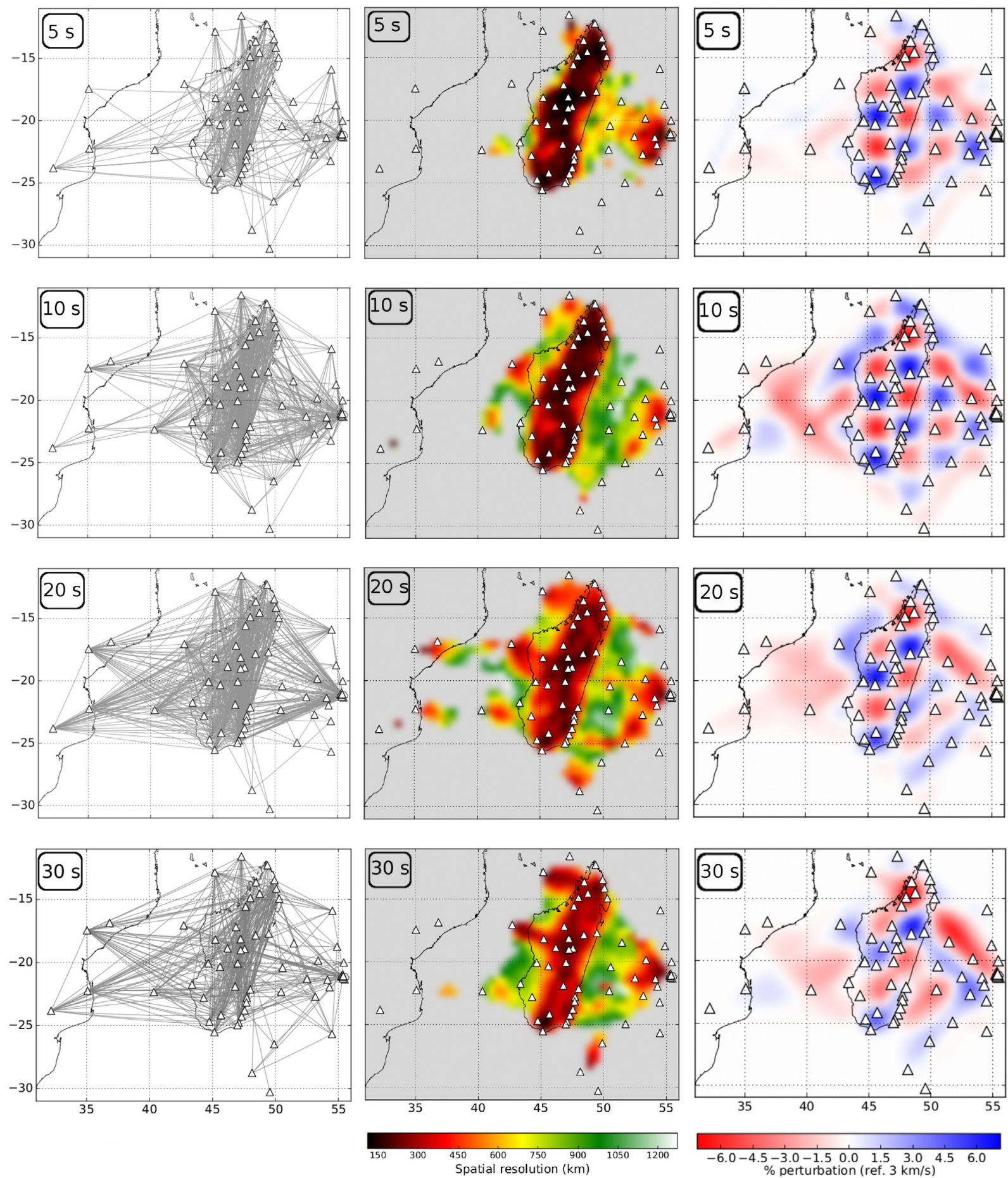

Figure 7. Results of resolution analysis at all four discrete periods considered in the study. Left-hand panel: path coverage at all periods, Middle panel: spatial resolutions at all periods and Right-hand panel: results of checkerboard test at all periods. They all show consistency in revealing the strength and limitations of tomographic maps obtained.

starting models used in the inversion, that is responsible for poorly constraining the deeper structure. Moreover, surface waves poorly constrain the strong velocity contrast over sharp boundary like the Moho; hence the Moho depth or upper mantle estimate based on surface wave dispersion analysis is a crude approximation. However, receiver function analysis can be combined with surface wave studies to accurately interpret them.
Unfortunately, this lack of resolution at deeper depths is reflected when combining nodal 1-D shear velocity structures to obtain shear velocity maps. In maps below $23 \mathrm{~km}$ depth, although shear velocities are relatively similar to those of previous studies, showing some resemblance to the lower crustal geometry and the tomographic maps at 25-30 s period range, they appear too smooth for any meaningful interpretation (see Fig. S5 in Supplementary information). The 


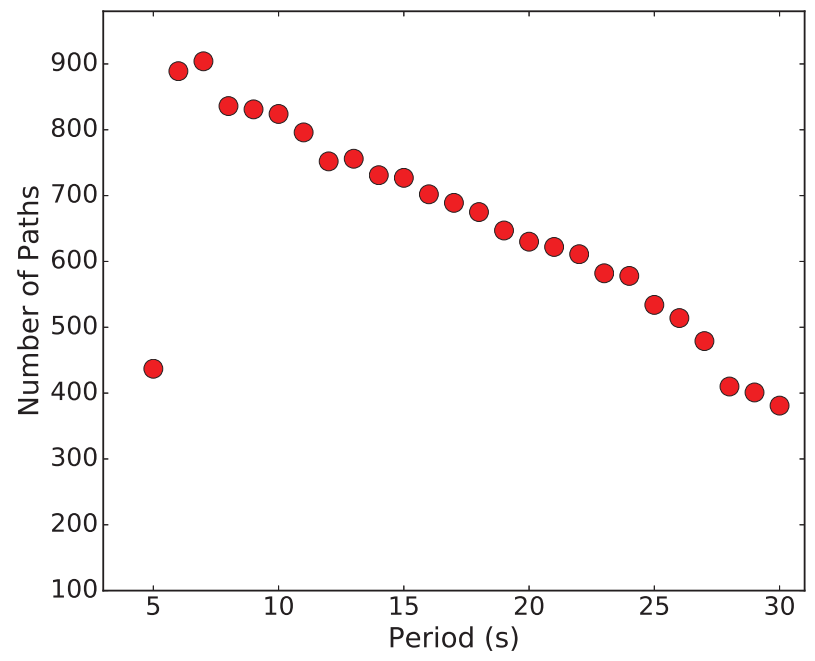

Figure 8. The number of interstation paths available at periods 5-30 s after applying the selection criteria.

variability of the final shear velocity models at these depths (red envelope in Fig. 10) is greater than the lateral heterogeneity in the maps. Based on these shortcomings, we present only shear velocity maps of the sedimentary layer, the upper and middle crust down to $23 \mathrm{~km}$ depth where we obtain a more reliable velocity structure (Figs $12 \mathrm{a}-\mathrm{d}$ ).

\section{RESULTS AND DISCUSSION}

Rayleigh-wave group-velocity maps in Figs 9(a)-(d) and shear velocity inversion results in Figs 11, 12(a)-(d) and 13(a)-(d) present the regional model of crustal velocity structure across Madagascar.

\subsection{Group velocity tomographic maps}

In this section, we explain the obtained group velocity tomographic maps in light of the region's surface geology and major tectonic features. Here, sensitivity is defined as the variation in group velocity caused by a small variation in shear-wave speed at a given depth. The sensitivity of surface waves at different periods to the earth structure varies with depth. Longer periods sample deeper structures while shorter periods, shallow features. As a guide to the interpretation of our tomographic maps, Fig. 14 shows Rayleigh wave group velocity sensitivity kernel at periods 5, 10, 20 and $30 \mathrm{~s}$. The sensitivity kernels show both positive and negative dependence on shear wave velocity for all periods.

Unlike in most ambient noise studies, at all periods of our tomographic maps (Fig. 9), group velocity varies rather widely (range of at least $1.4 \mathrm{~km} \mathrm{~s}^{-1}$ ), possibly indicating a higher data influence on the results as already pointed out and thus, restrict the spatial smoothing in the inversion which gives undesired heavily smoothened images of the subsurface.

At the shorter periods $(\sim 5-10 \mathrm{~s})$, group velocities are mainly influenced by the most shallow features (sedimentary and upper crustal structures), with low-velocity anomalies being a credible indicator of sedimentary basins and high-velocity anomalies reflect mountain ranges. On the other hand, at the intermediate period of $\sim 20 \mathrm{~s}$, group velocities are responsive to middle and lower crustal shear velocities. At longer periods ( $\geq 30 \mathrm{~s}$ ), group velocities become more representative of crustal thickness and uppermost mantle structure. Because of the large velocity contrasts across the Moho, group velocities should vary approximately inversely with crustal thickness. In all, the period range (5-30 s) considered in this study will allow sampling of the shallow structures (sedimentary and crustal structures) which is the principal target of the study.

Generally speaking, our group velocity maps across all periods show striking correlation with the known surface and subsurface geological features of the study region. In Fig. 9, we clearly see at short periods $(5-10 \mathrm{~s})$ the signature of the sedimentary basins within the western third of Madagascar and those of highlands within the Precambrian shield. The velocity anomalies at these periods represent structures at depths of about $0-18 \mathrm{~km}$ and are generally characterized by low group velocities $\left(<2.9 \mathrm{~km} \mathrm{~s}^{-1}\right)$ to the west. Along the western coast, we can distinguish three main velocity anomalies: (1) a low-velocity zone along the southwestern coast extending both north and eastward. This correlates with the location of the Morondava basin, characterized by Carboniferous to Jurassic sediments that may reach an average thickness of about $6-8 \mathrm{~km}$ (Andriampenomanana et al. 2017), (2) a narrow relatively lengthy patch of low-velocity anomaly along the northwestern coast coinciding with the Mahajanga basin and (3) a low velocity region just around the northern tip of the island correlating well with the location of the Antsirinana basin. All three low velocity anomalies are visible over the period range from 5 to $20 \mathrm{~s}$ and only start fading away at the $20 \mathrm{~s}$ period. This suggests that the thickness of the sedimentary deposits in the three distinct sedimentary basins may be larger than those obtained by Andriampenomanana et al. (2017) and others. Antsirinana basin, having a thickness of roughly $5-8 \mathrm{~km}$ (Andriampenomanana et al. 2017), may be too shallow to be seen in the $20 \mathrm{~s}$ map. Thus, the late Cenozoic alkaline intraplate volcanism that occurred in the northern part of Madagascar seems to be a more plausible explanation for the northernmost low velocity zone in the $20 \mathrm{~s}$ tomographic map. Although previous studies (e.g. Andriampenomanana et al. 2017; Pratt et al. 2017; Rindraharisaona et al. 2017) have imaged these basins, their shape and extent appear to have been better captured in this study. The shortest period (10 s) phase velocity map of Pratt et al. (2017) shows the Morondava basin as a sharp low velocity zone confined to the southwestern region of the island but poorly distinguished between the other two basins towards the north. On the other hand, our short period (5-10 s) group velocity maps have shown the Morondava basin as a relatively wide low velocity anomaly that extends well above $20^{\circ} \mathrm{S}$, the Mahajanga basin as a narrow semi-continuous patch of low group velocity along the northwestern flank and the Antsirinana basin as a small piece of low velocity anomaly just at the northern tip of the island (Figs $9 \mathrm{a}$ and $\mathrm{b}$ ). In their $20 \mathrm{~s}$ phase velocity map, there are no anomalies corresponding to the sedimentary basins, whereas weak signatures of the Morondava and Mahajanga basins can be seen as faint patches of low velocities in our group velocity map at $20 \mathrm{~s}$, pointing towards a more thicker sediments in these basins. The maps of sediment thickness and average shear velocity in sedimentary basins computed by Andriampenomanana et al. (2017) from joint inversion of receiver functions and surface wave data do not allow for the investigation of variations in these anomalies with depth, hence limit a direct comparison with our group velocity maps. Similarly, a direct comparison of our results with those of Rindraharisaona et al. (2017) is restricted as their study was confined to the southern part of Madagascar and did not present surface wave tomographic maps of the region. Away from the sedimentary basins, higher velocities appear to dominate the Precambrian block of the island which has been considerably uplifted and faulted. The highest velocity anomalies are observed at the central part of the map that corresponds to Madagascar's central highlands and just 

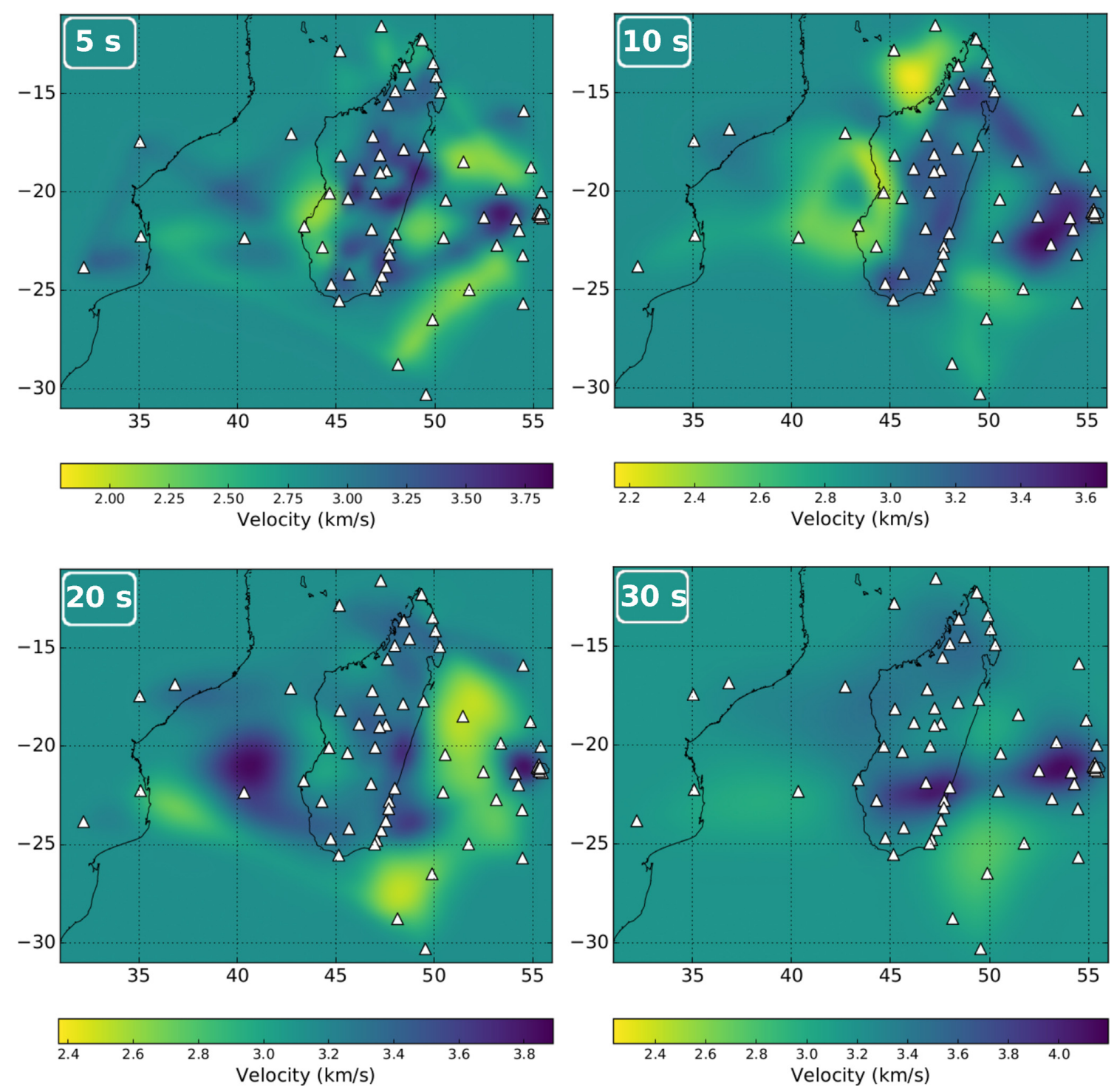

Figure 9. Rayleigh wave group velocity maps at periods 5, 10, 20 and $30 \mathrm{~s}$. The white triangles indicate seismic broad-band stations used in the study. The Madagascar island, occupying centre position and enclosed by solid black line is best resolved.

Table 2. Selected regions for 1-D shear-wave velocity inversion using a range of starting models.

\begin{tabular}{lll}
\hline Region & \multicolumn{1}{c}{ Description } & \multicolumn{1}{c}{ Age } \\
\hline Region 1 & Northern Madagascar Alkaline Province (NMAP) & Cenozoic \\
Region 2 & Southwestern Madagascar Alkaline Province (SMAP) & Cenozoic \\
Region 3 & Morondava Basin (MB) & Carboniferous-Jurassic \\
Region 4 & Bemarivo terrane (BT) & Neoproterozoic \\
Region 5 & Antananarivo terrane (AT) & Neoarchean \\
Region 6 & Anosyen Androyen terrane (AAT) & Paleoproterozoic \\
\hline
\end{tabular}

below the northern tip which coincides excellently with the location of the highest point in Madagascar: Maromokotro mountain in the Tsaratanana Massif. In the 10 s period map, along the junction between the sedimentary basin and the Precambrian block, the distribution of group velocity appears more uneven, pointing at a more complicated structure in the upper crust.

The group velocity map at $20 \mathrm{~s}$ samples structures at a typical depth range $\sim 10-30 \mathrm{~km}$ (middle and lower crust). Here, fast velocity anomalies continue to persist in the Precambrian basement, but unlike in the $10 \mathrm{~s}$ model, velocity variation is not uniform. It appears faster $\left(>3 \mathrm{~km} \mathrm{~s}^{-1}\right)$ in the Antananarivo and Bemarivo terranes, and along the eastern margin where the Antogil and Masora Cratons are located (Fig. 1). All of these terranes, apart from the Bemarivo terrane which is a Proterozoic Belt, are Archean. These faster velocities observed for Archean Cratons may imply a cooler crust with lower porosity compared to their Proterozoic counterparts. However, we cannot confirm the reason for the similarly faster velocities at the juvenile Neoproterozoic Bemarivo Belt in northern Madagascar.

For this study, the effects of variations in crustal thickness are best observed in the $30 \mathrm{~s}$ Rayleigh wave group-velocity map. Thick crust 
(a) Region 1
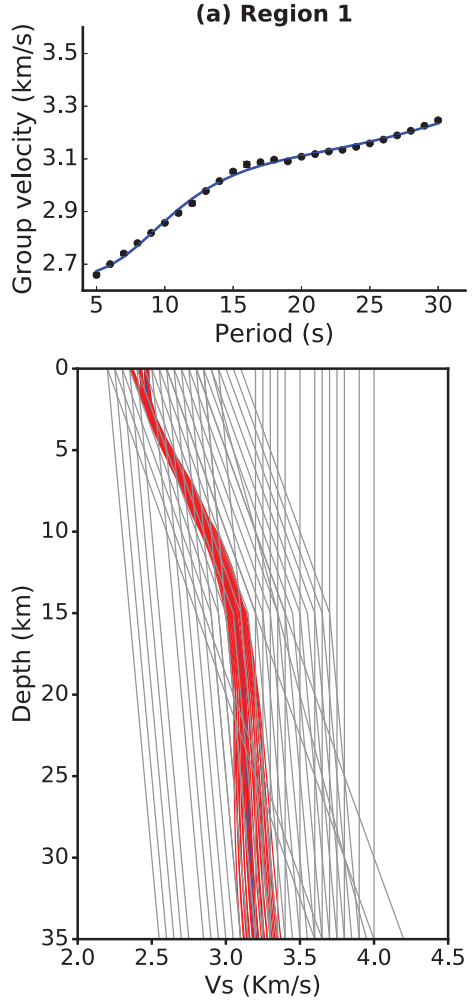

(d) Region 4
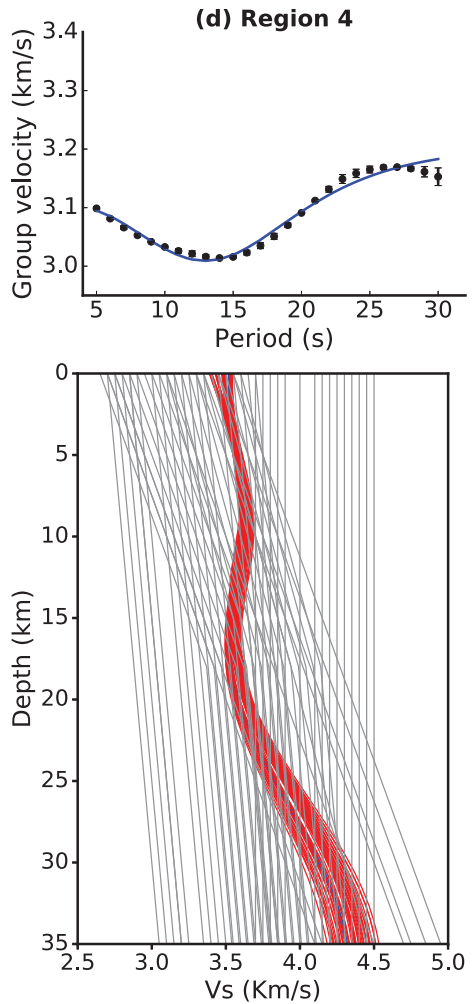

(b) Region 2
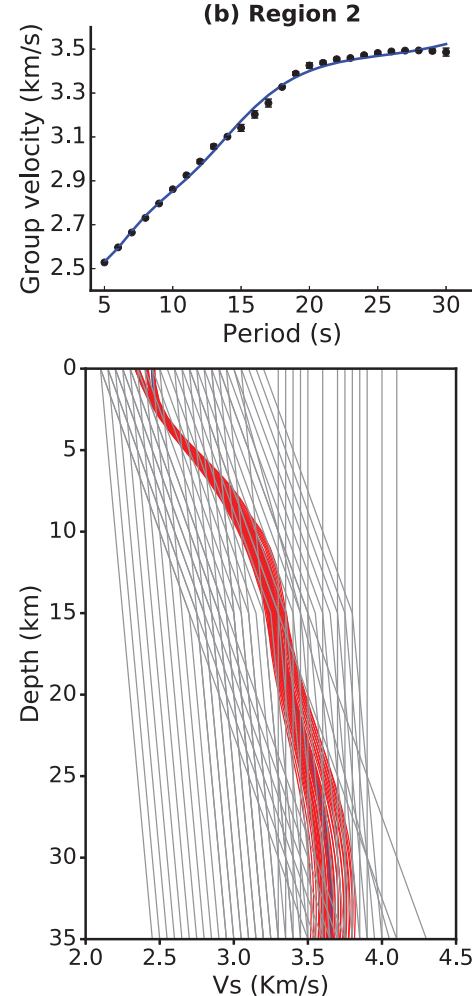

(e) Region 5
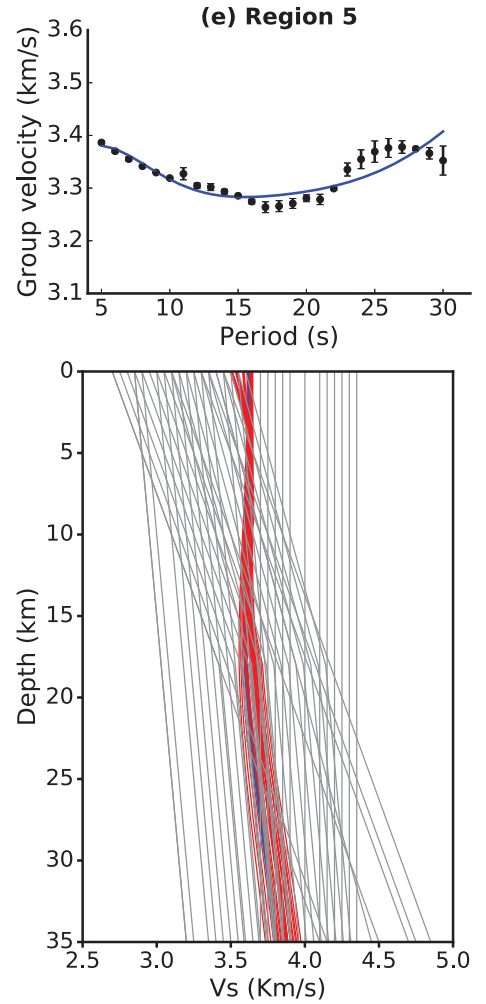

(c) Region 3
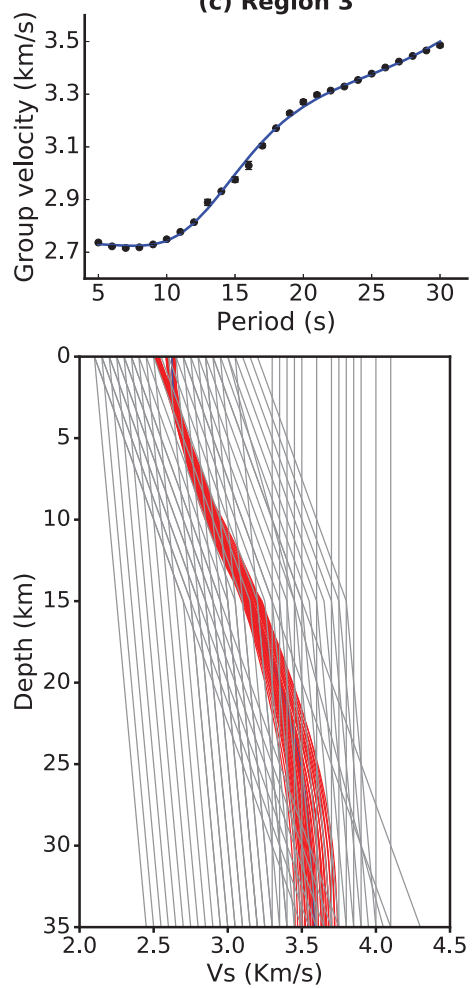

(f) Region 6
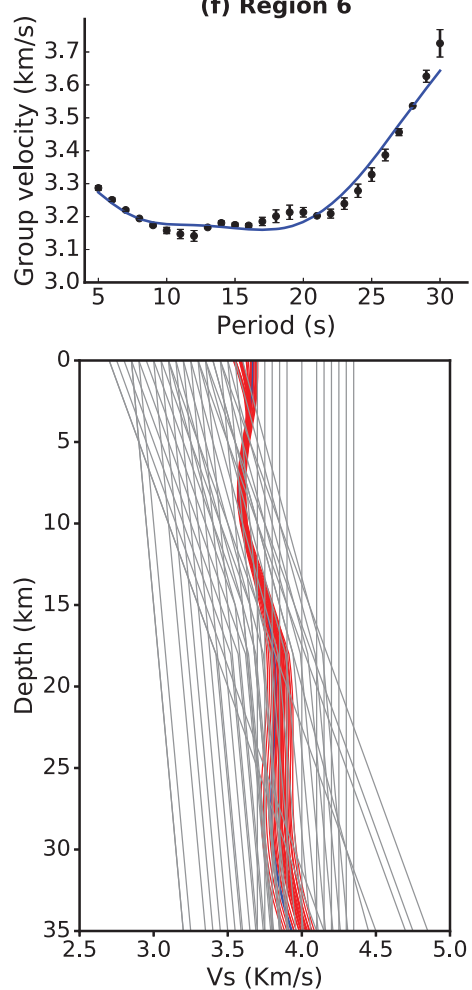

Figure 10. Shear wave velocity inversion result for regions 1-6 (Table 2) using a range of starting models. Top panel of each of (a)-(f) shows the average observed dispersion curves (black circles) and associated theoretical dispersion curves (blue lines) while the bottom panels show starting shear velocity models in grey, and in red the envelope of the final velocity models after inversion. The theoretical dispersion curves were predicted from the final models in blue. Error bars indicate the standard deviation of group-velocity misfit for all periods. 
(a)

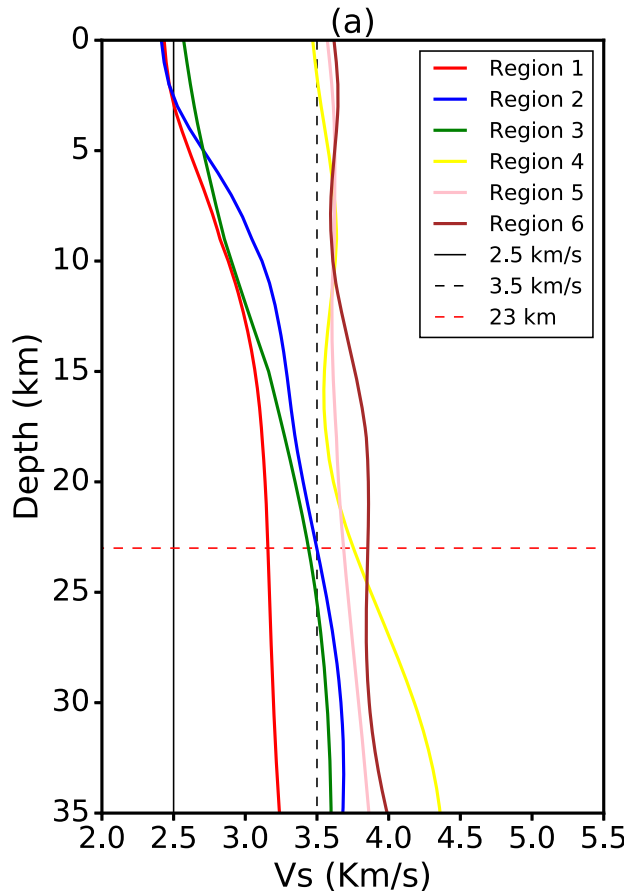

(b)

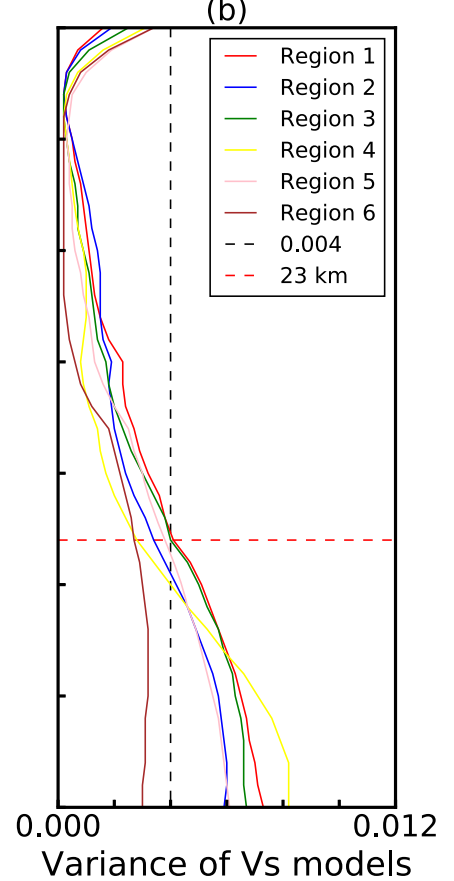

(c)

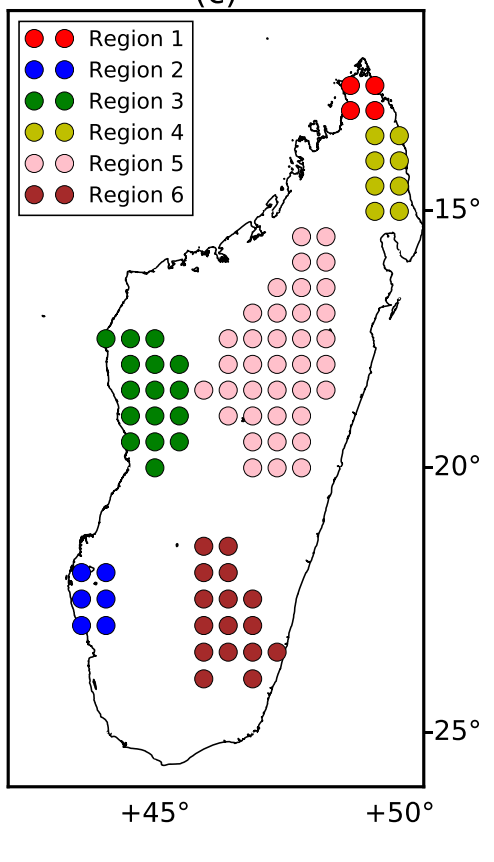

Figure 11. (a) Mean and (b) variance of the recovered shear velocity envelopes in Fig. 10 for regions 1-6. (c) Location of points within each region from which dispersion curves were extracted and averaged for the shear velocity inversion.

manifests itself as low-velocity anomalies and vice versa. Although the resolution of our $30 \mathrm{~s}$ map is not as good as those of shorter periods, we can still observe the strongest low-velocity anomaly around central Madagascar where the Moho is deepest and extends to depths greater than $40 \mathrm{~km}$ (Andriampenomanana et al. 2017). Gradual thinning of the crust away from the centre as we found here has also been reported by several authors (e.g. Andriampenomanana et al. 2017; Pratt et al. 2017; Rindraharisaona et al. 2017). Broadly, our results reflects this trend; however, moving towards southern Madagascar, an almost E-W trending high group velocity anomaly, which appears to coincide with the location of the Ranotsara zone (a composite structure with a prominent NW-SE trending brittle faulting along most of its length and a ductile deflection zone limited to its central segment) is observed. We interpret this relatively thinned crust to be related to the Ranotsara shear zone (re)activation during the opening of the Mozambique channel which now represents a topographic boundary (normal fault) between southern and central Madagascar (Lardeaux et al. 1999).

Along the eastern rifted margin, we observe an almost steady variation in group velocity across all periods. However, slightly faster group velocities $\left(\sim 3.4 \mathrm{~km} \mathrm{~s}^{-1}\right)$ appear to trend the central segment compared to the southern and northern segments in the short period ( 5 and $10 \mathrm{~s}$ ) maps (Figs 9a and b). A reversed scenario is seen at the $30 \mathrm{~s}$ period (Fig. 9d). These observations suggest a slightly thicker crust beneath the central areas compared to the southern and northern parts. Cretaceous widespread flood basalts currently found in this peripheral region of the island are believed to have once covered the entire island (Storey et al. 1995). Erosion, amongst other agents, has been cited as a process via which most of these lava were removed from majority of the island but the amount of lava removed is still uncertain. This perceived uneven erosion of the crust beneath the region alongside the rifting event that triggered the breakup of
Madagascar and Greater India may accommodate our observations along this region. Although our main region of interest in this study is the Madagascar island where resolution is $\sim \leq 250 \mathrm{~km}$, we make extra effort to lightly describe and interpret the velocity anomalies observed in the passive continental margin, just off the east coast of Madagascar. Within this region developed from continental rifting and breakup, resolution degrades slightly to $\sim 300 \mathrm{~km}$. Across all four periods investigated, unlike the adjacent eastern coast of Madagascar, this area is dominated by slow group velocities (Figs 9 a-d). This striking difference in group velocity variation is most likely due to the compositional differences between oceanic and continental materials. Two isolated high velocity anomalies are found in the $5 \mathrm{~s}$ map, showing group velocities of $\sim 3.3-3.7 \mathrm{~km} \mathrm{~s}^{-1}$ (Fig. 9a). The first and much larger one is located around $\sim 22^{\circ} \mathrm{S}$, inbetween Madagascar and La Réunion island while the second one lies just below $\sim 15^{\circ} \mathrm{S}$. The larger fast velocity anomaly persists across all periods, extending into La Réunion island in the 10, 20 and $30 \mathrm{~s}$ maps (Figs 9b-d). We attribute the slow velocities in the 5 and $10 \mathrm{~s}$ maps to oceanic sediments while the prevalent high velocity seen across all periods may be due to consolidated localized igneous rocks that extend deep in the region.

Finally, the velocity anomalies observed across all periods in the Mozambique channel, some parts of the Mascarene basin and other regions outside the main Madagascar island where they have not been interpreted are relatively poorly resolved due to sparse data coverage, and as such their shape and limits are considered not reliable. This is further validated by the synthetic checkerboard test which shows that within these locations velocity anomalies cannot be successfully resolved.

We think it is worth to discuss here some of the limitations inherent in the ray theory of wave propagation underlying the tomographic method and nature of data set used. As a general 

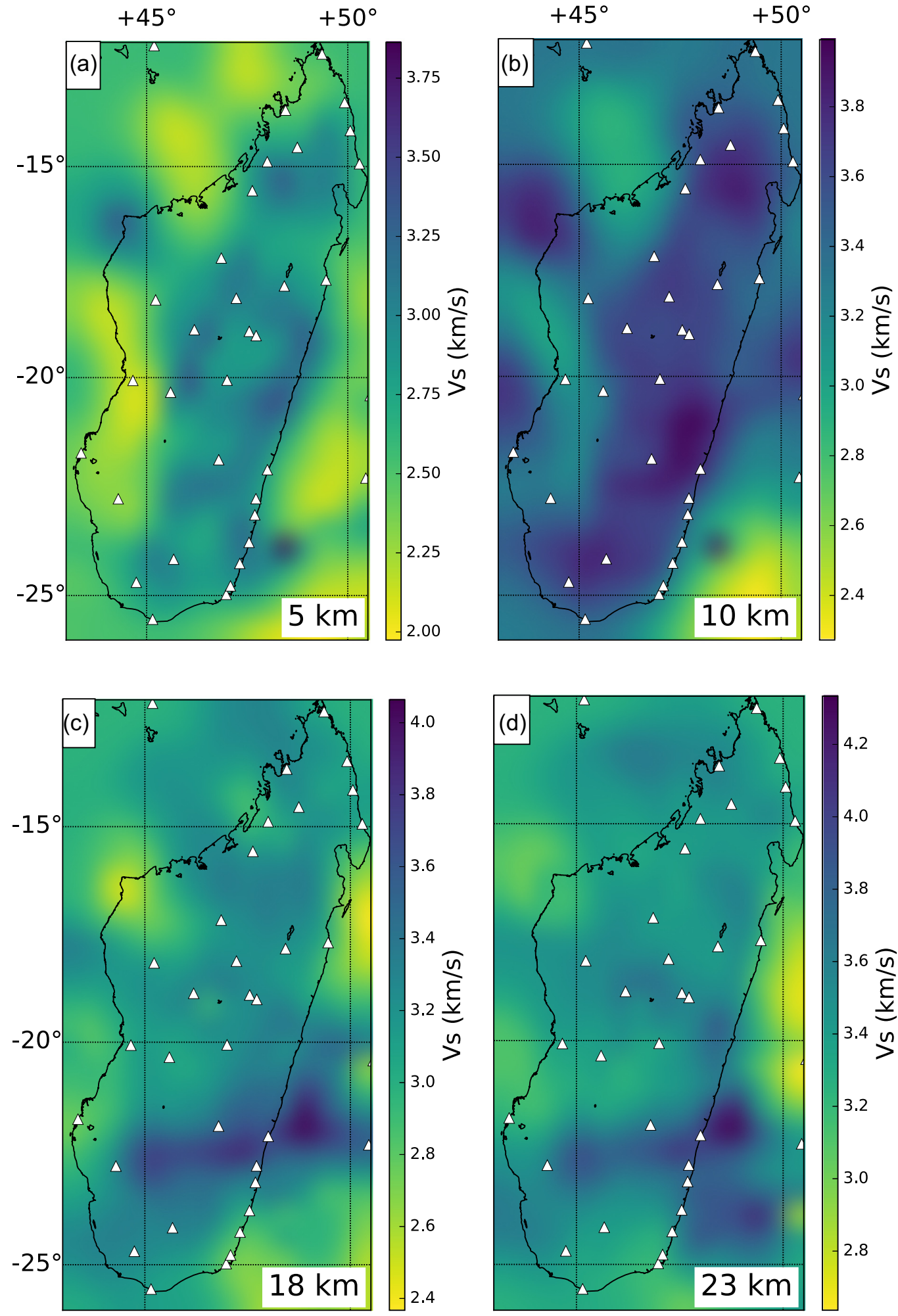

Figure 12. Shear wave velocity maps in the sedimentary layer and crust at depths of 5-23 km (a-d). Regions outside the island are unconstrained. The white triangles indicate some of the seismic broad-band stations used in the study.

rule, the ray theory assumes surface wave propagation along the great circle paths between station pairs, neglecting the effects of off-great-circle paths, that is waveform complexities due to smallscale heterogeneities of the medium surrounding the path. Although their effects on dispersion measurements are much less for shorter ray paths, at short periods $(<5 \mathrm{~s})$, it is still important to consider them in order to account for small-scale group velocity structures. Thus, their effects may have biased our tomographic images at short periods to some degree along some ray paths, especially those connecting the OBS stations sampling outside the island 

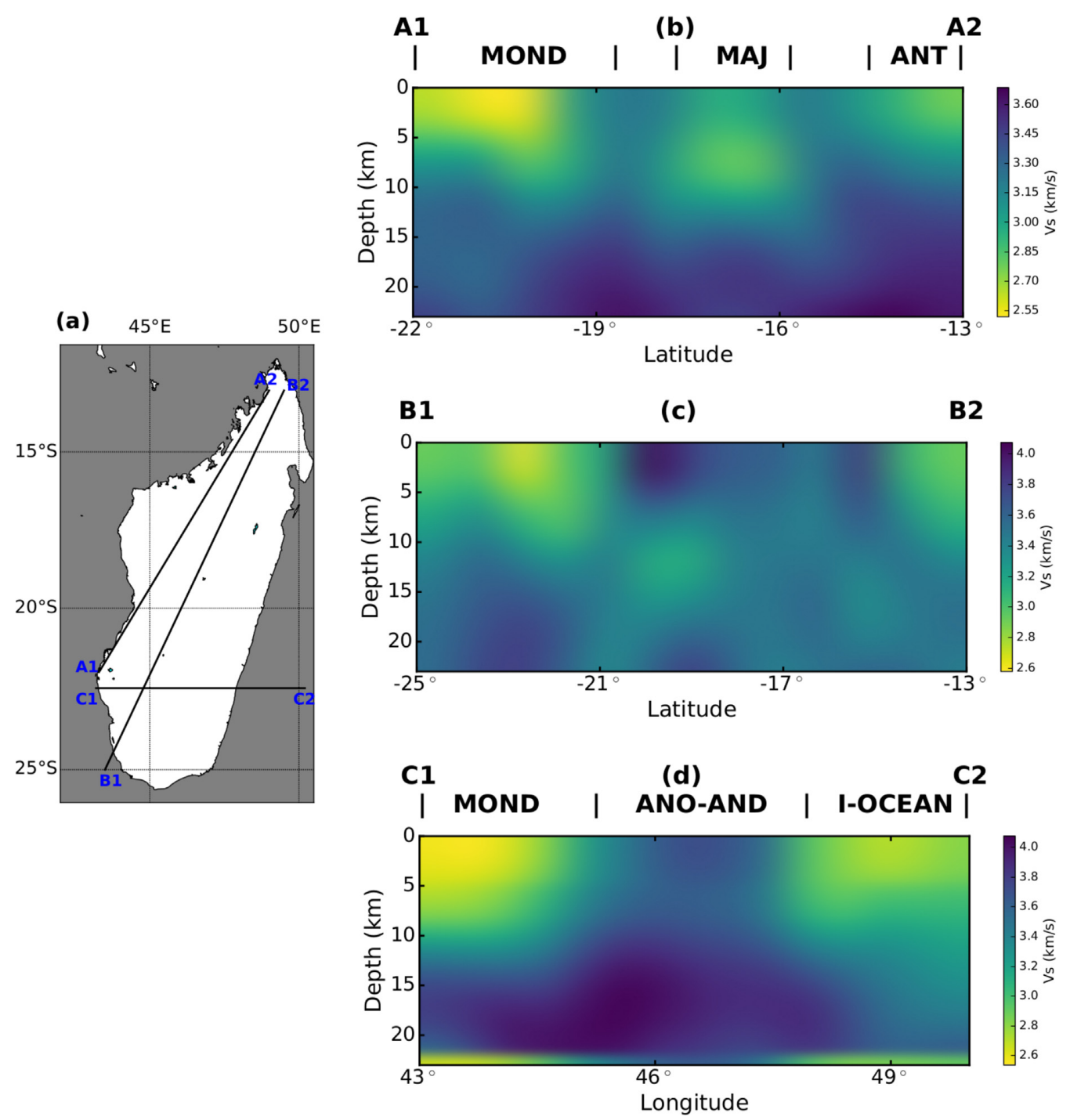

Figure 13. (b)-(d): Cross-sections through the shear-velocity model shown in Fig. 12 to $23 \mathrm{~km}$ depth. MOND, Morondava basin; MAJ, Mahajanga basin; ANT, Antsirinana basin; ANOS-AND, Anosyen-Androyen terrane; I-OCEAN, Indian Ocean. Sections are shown on the map of the study area in (a).

area of our study region. Although their effects cannot be completely ruled out, we firmly think the sedimentary features inside the main island are clearly revealed to an extent that had never been achieved in previous Rayleigh-wave velocity maps. In any case, it still deserves further investigation, accounting for these details in future.

\subsection{Shear velocity structure}

With the ensemble of 464 nodal 1-D shear velocity structures, we assemble 3-D shear velocity models of the region interpolating from the spatial grids. Figs 12(a)-(d) show the shear wave velocity model at depths of 5, 10, 18 and $23 \mathrm{~km}$, displayed using an absolute velocity scale.

The structures in the resulting 3-D shear wave velocity models are quite similar to those observed in the group velocity maps (Fig. 9), especially at short periods $(\leq 10 \mathrm{~s})$. The $5 \mathrm{~km}$ map displayed in Fig. 12(a) is the shallowest depth of shear velocity maps ever reported for Madagascar, thanks to the inclusion of OBS data. It shows the sedimentary layer and uppermost part of the crust, with shear velocities ranging from about 2.3 to $3.6 \mathrm{~km} \mathrm{~s}^{-1}$, the lowest values typical of loosed sediments in the sedimentary basins in the western third of the island. Although surface waves are not the best means of imaging shallow basin structures, both cross-sections along selected profiles through the shear velocity model (Figs 13ad) and velocity maps (Figs 9 and 12) at the shortest periods (5 and $10 \mathrm{~s}$ ) and shallowest depths (5 and $10 \mathrm{~km}$ ) clearly delineate the lateral extent and depth of the three sedimentary basins. Cross section A1-A2 along the length of the western third of the island shows low velocities corresponding to the Morondava and Mahajanga basins reaching depths of around $\sim 10 \mathrm{~km}$ and those correlated with the Antsirinana basin fading away after $\sim 5 \mathrm{~km}$ (Fig. 13b). Along profile $\mathrm{C} 1-\mathrm{C} 2$ cutting across the southern part of the island from west to east, we observe the southwestern low velocity anomaly coinciding with the location of the Morondava basin extending beyond $\sim 45^{\circ} \mathrm{E}$ (Fig. $13 \mathrm{c}$ ). From these observations, we infer the Morondava basin in the southwestern coast to be the broadest and Antsirinana basin at the northern tip to be the narrowest. We also come to the conclusion that the Morondava and Mahajanga basins host the thickest sedimentary rocks in the study region. The distribution of 


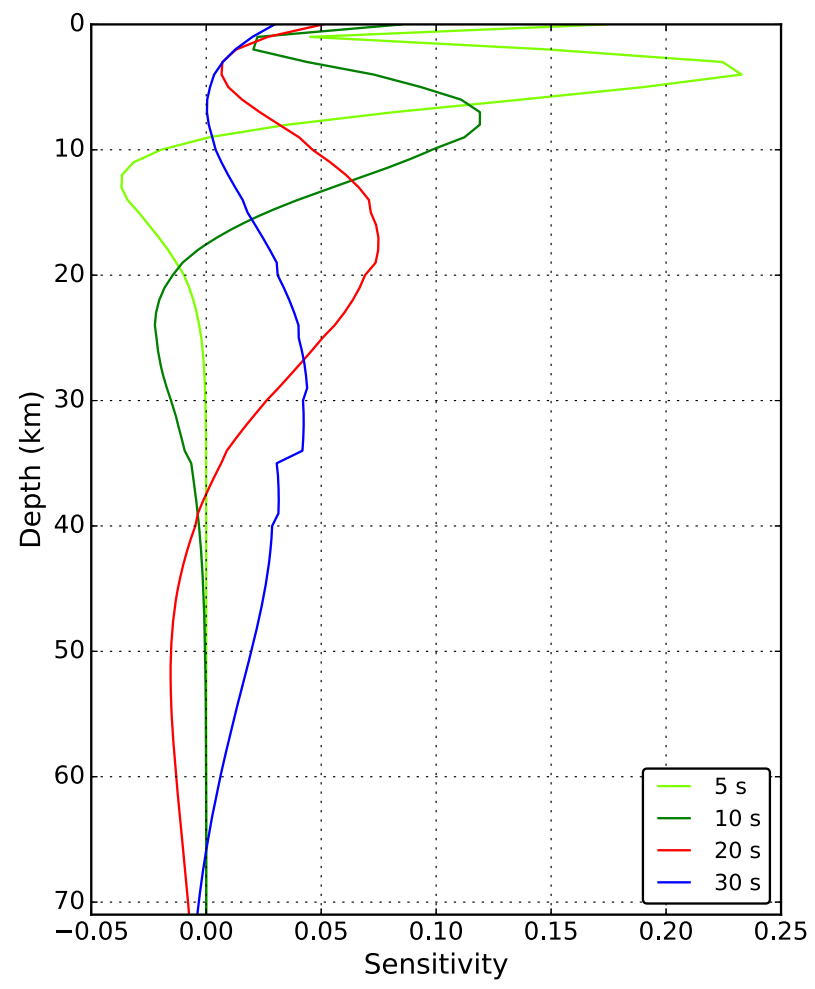

Figure 14. Sensitivity kernels of Rayleigh wave group velocity at periods $5,10,20$ and $30 \mathrm{~s}$.

shear wave velocities at depths of 5 and $10 \mathrm{~km}$ appears to mark the boundary between the entire west coast which makes up one third of the island and the remaining two-thirds of the island: lower velocities in the sedimentary basins and higher velocities in the Precambrian crystalline basement which consist mainly of the Antananarivo, Anosyen-Androyen, Vohibory and Bemarivo terranes. The shallow velocity distribution in Madagascar captured in our maps is consistent with that obtained by Pratt et al. (2017) but more apparent, with an almost uniform higher velocities in the entire Precambrian shield. Cross section B1-B2 (Fig. 13c) traversing the Precambrian shield shows the region to be dominated by fast shear velocities $\left(\sim 3.3-4.0 \mathrm{~km} \mathrm{~s}^{-1}\right)$. In particular, a very high velocity anomaly $\left(\sim 3.8 \mathrm{~km} \mathrm{~s}^{-1}\right)$ seen at shallow depths around- $19^{\circ} \mathrm{S}$ correlates well with the position of Madagascar's central highlands. At $23 \mathrm{~km}$ depth (Fig. 12d), roughly corresponding to the transition zone from the middle to lower crust in the Precambrian shield and to the deeper crustal structure and/or upper mantle in the sedimentary basins, we start observing weak reverse velocity anomalies with respect to the velocities in the upper crust. This trend appears more apparent in cross sections A1-A2 and B1-B2 of Fig. 13. Slightly reduced velocities in the eastern two-thirds of the island are likely associated with the crustal roots of the central and Northern highlands while the relatively high velocities in the sedimentary basins likely correlate with lower crust and uppermost mantle velocities of the Madagascar plate. A similar trend is seen in the velocity models obtained by Pratt et al. (2017).

The average shear velocity structure for regions $1-6$ are shown in Figs 10 and 11. The mean of the recovered shear velocity models (red envelopes in the bottom panels of Fig. 10) obtained using a wide range of starting models is presented in Fig. 11(a), and they represent the average structure beneath the different geologic and tectonic units. The range of slow shear velocities $\left(2.4-3.5 \mathrm{~km} \mathrm{~s}^{-1}\right)$ observed in the top $23 \mathrm{~km}$ beneath the sedimentary basin are mostly consistent with the values obtained by Andriampenomanana et al. (2017) in their joint inversion of receiver functions and Rayleigh wave phase-velocity measurements. They obtained average crustal shear velocity to vary from 2.8 to $3.6 \mathrm{~km} \mathrm{~s}^{-1}$. These slow crustal velocities beneath regions 1-3 are typical of an upper crust underlying a sedimentary layer and implies that most of the lower crust has been removed. In general, the shear wave velocity structure of the Malagasy platform reveals a varied velocity-gradient within the top $23 \mathrm{~km}$ (Fig. 11a). The west coast having a sedimentary cover and where regions 1-3 are located, shows high velocity-gradients, with shear velocity at the base of the high gradient layer (12-14 km) reaching around $3.2-3.4 \mathrm{~km} \mathrm{~s}^{-1}$. Beyond this depth, there is a gradual reduction in velocity-gradient signifying a more stable consolidated structure. We infer the high velocitygradients to be a result of decreasing fracture density due to the increasing overburden and to the infilling of basins by sediments occasioned by the two different rifting events that shaped the Western third of Madagascar (e.g. Coffin \& Rabinowitz 1988; Piqué 1999b; Schandelmeier et al. 2004): (1) the Permo-Triassic continental failed rift that thinned the eastern part of the Morondava basin and (2) the Jurassic breakup from Africa that further thinned the western Morondava basin that was earlier stretched in the Karroo. These rifting events and penultimate breakup from Africa are most likely responsible for the removal of the lower crust beneath regions $1-3$.

In the remaining two-thirds of the island, on the eastern side, where regions 4-6 are located, we observe a reverse scenario (relative to the west coast) of an almost constant shear velocity (3.5$3.75 \mathrm{~km} \mathrm{~s}^{-1}$ ) in the entire top $23 \mathrm{~km}$ with exception to region 6 where there is a sudden increase in velocity-gradient around the $12 \mathrm{~km}$ depth resulting in a high shear velocity $\left(3.95 \mathrm{~km} \mathrm{~s}^{-1}\right)$ at the $23 \mathrm{~km}$ depth. Crustal velocity differences generally reflect variations in a range of rock characteristics and conditions that include composition, temperature, partial melt content, fracturing and faulting of the crustal rocks, etc. The almost steady shear velocities observed may be indicative of compositionally homogeneous Archean and Proterozoic terranes in Madagascar and certainly not age dependent, especially within the top $12 \mathrm{~km}$. In particular, the shear velocity structure for all three regions show shear velocities of $\sim 3.6 \mathrm{~km} \mathrm{~s}^{-1}$ within the upper crust $(\sim 0-12 \mathrm{~km})$. Within the middle crust $(\sim 12-$ $20 \mathrm{~km}$ ), shear velocity is slightly reduced to $3.55 \mathrm{~km} \mathrm{~s}^{-1}$ for region 4 , remains unchanged in region 5 and increased by $0.1 \mathrm{~km} \mathrm{~s}^{-1}$ in region 6 . In the remaining part of the crust where we obtained reliable result, the structure beneath regions 4 and 5 reveals shear velocities of 3.7 and $3.65 \mathrm{~km} \mathrm{~s}^{-1}$, respectively, while region 6 gives the highest shear velocity of $3.95 \mathrm{~km} \mathrm{~s}^{-1}$. These values are broadly in concordance with those from several stations: BARY, MS12, MKVA, MS11, MS12, ZAKA, ZOBE, etc., within these regions obtained by Rindraharisaona et al. (2017) and Andriampenomanana et al. (2017).

From laboratory experiments, mafic lithologies found in the crust have higher shear velocities $\left(>3.9 \mathrm{~km} \mathrm{~s}^{-1}\right)$ than intermediate-tofelsic lithologies, having lower shear wave velocities $\left(<3.9 \mathrm{~km} \mathrm{~s}^{-1}\right.$, e.g. Holbrook et al. 1992; Christensen \& Mooney 1995). We, therefore, interpret the upper and middle crustal layers in all three regions to consist predominantly of intermediate-to-felsic lithologies. Although there is no simple correlation between Poisson's ratio and felsic and mafic rock compositions; however, the similar Poisson's ratios obtained at seismic broadband stations SBV $(0.25 \pm 0.02)$, 
SOLA $(0.24 \pm 0.02)$ and FOMA $(0.25 \pm 0.03)$ in regions 4,5 and 6 , respectively, by Andriampenomanana et al. (2017) leans towards this conclusion. Around the $23 \mathrm{~km}$ depth, in regions 4 and 5, the slightly higher shear velocities may indicate a transition from the middle to lower crust. In region 6 made up of Palaeoproterozoic ( 2.0-1.8 Ga) gneissic basement and sequences of Neoarchean and Palaeoproterozoic platform sediments, the sharp spike in shear velocity around the $12 \mathrm{~km}$ depth may be attributed to solidified mafic intrusions at mid- to upper-crustal depths. While some studies have avowed a thicker Proterozoic crust (e.g. Durrheim \& Mooney 1991, 1994), in Madagascar, there is still no consensus on which of the Archean or Proterozoic crust is thicker. Rindraharisaona et al. (2017), from shear velocity structures obtained in the southern part of Madagascar, made a strong argument for a thicker Archean crust compared to the Proterozoic one. They interpreted the shear velocities $\left(\sim 3.7 \mathrm{~km} \mathrm{~s}^{-1}\right)$ for stations RUM4, RUM5, FOMA, MS12, MS11, etc., within the Proterozoic region 6 to indicate the presence of felsic-to-intermediate lower crust and further argued that even if there were to be a mafic lower crust, it must have been delaminated by the high-temperature metamorphism that affected the southern part of Madagascar in 560-530 Ma (e.g. Jöns \& Schenk 2011). Although the depth extent of our shear velocity structures in regions $4-6$ is limited to only the top $23 \mathrm{~km}$ and does not allow for the determination of the crustal thicknesses in the regions, the fast shear velocity $\left(3.95 \mathrm{~km} \mathrm{~s}^{-1}\right)$ around the $23 \mathrm{~km}$ depth beneath region 6 may point towards a lower crust with mafic underplating. Rindraharisaona et al. (2017) have made their deduction from seismic stations located on the fringes of the region, whereas one of our stations (BKTA) lies at the centre of the region, and we have inverted the average of dispersion curves reconstructed at several grid points within the region (Fig. 11c) for the average structure. Other factors like the nature of data, method of analysis, inversion technique used, etc., which are different for the two studies can also possibly explain the discrepancy in both studies. We believe our data and approach should give a better approximation of the region's structure, especially of the shallow crust.

\section{CONCLUSION}

We have presented the first 2-D Rayleigh wave group velocity map of the entire Madagascar platform at periods between 5 and $30 \mathrm{~s}$ by cross-correlating approximately 1 -yr-long seismic noise data recorded by a total of 63 broad-band seismic stations from different seismic networks deployed in Madagascar, Mozambique and surroundings. The inclusion of data from 16 OBS stations of the RHUM-RUM seismological experiment has further improved the quality of the images, especially at short to medium range periods and along the eastern boundaries of the island with spatial resolution varying between 150 and $200 \mathrm{~km}$ within the Madagascar block. However, at longer periods, resolution is diminished due to lower SNR of CCFs in the long-period band, especially those of island and OBS stations, resulting in the rejection of a significant number of ray paths. This shortcoming has ultimately limited the depth extent of both our shear velocity model and average shear velocity structures to a depth of $\sim 23 \mathrm{~km}$.

Rayleigh wave group velocity tomographic maps show distinct velocity anomalies correlated with the Morondava, Mahajanga and Antsiranana basins, central Madagascar highlands and Tsaratanana massif to the north of the island. The short period group velocity maps have imaged the sedimentary basins with a higher resolution, showing its details, compared to previous velocity maps. The low velocity anomalies associated with the two southernmost sedimentary basins persist up to the $20 \mathrm{~s}$ period tomographic map, corroborating results of some earlier studies alluding to a sediment thickness of more than $10 \mathrm{~km}$ in the south and thinning out towards the north and east (Besairie 1971; Boast \& Nairn 1982; Coffin \& Rabinowitz 1988). The structures seen in the 3-D shear wave velocity model are quite similar to those observed in the Rayleigh wave group velocity maps, mostly at short periods. The $5 \mathrm{~km}$ deep section is the shallowest depth of shear velocity map ever reported for Madagascar. It shows in great details the sedimentary layer and uppermost part of the crust, with shear velocities ranging from about 2.3 to $3.6 \mathrm{~km} \mathrm{~s}^{-1}$, the lowest values corresponding to loosed sediments in the sedimentary basins in the western third of the island while the highest to the fabrics of extensively deformed and metamorphosed rocks in the Precambrian Shield. Slightly reduced shear wave velocities found at $23 \mathrm{~km}$ depth within the eastern two-thirds of the island are associated with the crustal roots of the central and Northern Plateaus while the increased velocities that appear to dominate the sedimentary basins are indicative of an uplifted deep crustal structure or uppermost mantle unit beneath the region.

The six average 1-D shear wave velocity structures obtained span the greater part of the Precambrian shield of Madagascar and do not indicate a substantial difference in the crustal composition between the Archean and Proterozoic rocks, especially within the top $12 \mathrm{~km}$. They, however, suggest some interesting features, such as an intermediate-to-felsic upper and middle crust beneath all three Precambrian regions, a mafic intrusion in the middle crust down to a depth of $23 \mathrm{~km}$, among others. Although our current regional model of crustal velocity structure across Madagascar island could satisfactorily explain shallow crustal features up to $23 \mathrm{~km}$ depth, a more detailed 3-D shear wave velocity model of the region, delineating the entire crust and uppermost mantle structure from ambient noise tomography alone is feasible with the availability of more high quality data. In particular, data from stations of the SELASOMA project which were not publicly available at the time of carrying out this study will be helpful in this regard.

\section{Data statement:}

Data used are openly available at the data management centres of IRIS and other partner organizations. Further information can be obtained on request from the corresponding author.

\section{ACKNOWLEDGEMENTS}

First, we acknowledge the $\mathrm{PhD}$ fellowship awarded to Adimah by the Council of Scientific and Industrial Research (CSIR), India and The World Academy of Science (TWAS). Data used in this study were provided by the data management centres of IRIS, RESIF, GEOFON GSN and IPGP. The ObsPy Python Library (Beyreuther et al. 2010) and Seismic Analysis Code (SAC) were used to process the data. The figures were generated using the Matplotlib Python Library (Hunter 2007) and the Generic Mapping Tools (Wessel \& Smith 1998). Thanks to Drs R. Herrmann and B. Goutorbe for sharing the codes used here. We sincerely appreciate the editor Prof Huajian Yao and three anonymous reviewers whose constructive comments have greatly helped in improving the manuscript. We also thank Director, CSIR-National Geophysical Research Institute (Ref.No: 
NGRI/Lib/2019/Pub-118) and staff of NGRI-Seismological Observatory for creating an enabling environment at the institute where this work was carried out.

\section{REFER E N CES}

Andriampenomanana, F. et al., 2017. The structure of the crust and uppermost mantle beneath Madagascar, Geophys. J. Int., 210(3), 1525-1544.

Bao, X., Song, X. \& Li, J., 2015. High-resolution lithospheric structure beneath Mainland China from ambient noise and earthquake surfacewave tomography, Earth planet. Sci. Lett., 417, 132-141.

Barmin, M., Ritzwoller, M. \& Levshin, A., 2001. A fast and reliable method for surface wave tomography, Pure appl. Geophys., 158, $1351-1375$.

Barruol, G. \& Fontaine, F.R., 2013. Mantle flow beneath La RéUnion hotspot track from SKS splitting, Earth planet. Sci. Lett., 362, 108-121.

Barruol, G., Sigloch, K. \& group, R.-R., 2017. RHUM-RUM experiment, 2011-2015, code YV (Réunion Hotspot and Upper Mantle - Réunion's Unterer Mantel) funded by ANR, DFG, CNRS-INSU, IPEV, TAAF, instrumented by DEPAS, INSU-OBS, AWI and the Universities of Muenster, Bonn, La RéUnion, RESIF - Réseau Sismologique et géodésique Franàßais. Terrestrial seismic network, Ocean bottom seismic and hydroacoustic network. https://doi.org/10.15778/RESIF.YV2011.

Bell, S.W., Forsyth, D.W. \& Ruan, Y., 2015. Removing noise from the vertical component records of ocean bottom seismometers: results from year one of the Cascadia initiative, Bull. seism. Soc. Am., 105(1), 300-313.

Bensen, G.D., Ritzwoller, M.H., Barmin, M.P., Levshin, A.L., Lin, F., Moschetti, M.P., Shapiro, N.M. \& Yang, Y., 2007. Processing seismic ambient noise data to obtain reliable broad-band surface wave dispersion measurements, Geophys. J. Int., 169(3), 1239-1260.

Besairie, H., 1971. Tectonique de Madagascar. Tectonique de 1'Afrique, Sciences de la Terre UNESCO Paris, 549-558.

Besairie, H., 1973. Bràäve revue de volcanisme à madagscar Colloque surles régions volcaniques tropicales, Pub. Ass. Géogr., Madagascar, 18pp.

Beyreuther, M., Barsch, R., Krischer, L., Megies, T., Behr, Y. \& Wassermann, J., 2010. Obspy: a python toolbox for seismology, Seismol. Res. Lett., 81(3), 530-533.

Boast, J. \& Nairn, A., 1982. An Outline of the Geology of Madagascar, in the Ocean Basins and Margins, pp. 649-696, Springer.

Bowden, D.C., Kohler, M.D., Tsai, V.C. \& Weeraratne, D.S., 2016. Offshore southern California lithospheric velocity structure from noise crosscorrelation functions, J. geophys. Res., 121(5), 3415-3427.

Campillo, M. \& Paul, A., 2003. Long-range correlations in the diffuse seismic coda, Science, 299, 547-549.

Christensen, N.I. \& Mooney, W.D., 1995. Seismic velocity structure and composition of the continental crust: a global view, J. geophys. Res., 100, 9761-9788.

Coffin, M.F. \& Rabinowitz, P.D., 1988. Evolution of the conjugate east African-Madagascan margins and the western Somali Basin, Geol. Soc. Am. Spec. Pap. , 226,

Collins, A.S., 2006. Madagascar and the amalgamation of central gondwana, Gondwana Research, 9(1), 3-16.

Crawford, W.C., Stephen, R.A. \& Bolmer, S.T., 2006. A second look at lowfrequency marine vertical seismometer data quality at the OSN-1 site off Hawaii for seafloor, buried, and borehole emplacements, Bull. seism. Soc. Am., 96(5), 1952-1960.

Crawford, W.C. \& Webb, S.C., 2000. Identifying and removing tilt noise from low-frequency $(<0.1 \mathrm{~Hz})$ seafloor vertical seismic data, Bull. seism. Soc. Am., 90(4), 952-963.

de Wit, M., 2003. Madagascar: heads it's a continent, tails it's an island, Ann. Rev. Earth planet. Sci, 31, 213-248.

Durrheim, R.J. \& Mooney, W.D., 1991. Archean and Proterozoic crustal evolution: evidence from crustal seismology, Geology, 19(6), 606-609.

Durrheim, R.J. \& Mooney, W.D., 1994. Evolution of the Precambrian lithosphere: seismological and geochemical constraints, J. geophys. Res., 99(B8), 359-374.
Emerick, C. \& Duncan, R., 1982. Age progressive volcanism in the Comores Archipelago, western Indian Ocean and implications for Somali plate tectonics, Earth planet. Sci. Lett., 60, 415-428.

Fourno, J. \& Roussel, J., 1994. Imaging of the Moho depth in Madagascar through the inversion of gravity data: geodynamic implications, Terra Nova, 6, 512-519.

GAF-BGR, 2008. Final report. explanatory notes for the vohibory domain southwest madagascar, Réalisation des travaux de cartographie géologique de Madagascar, révision appro-fondie de la cartographie géologique et miniàäre aux échelles $1 / 100000$ et 1/500000 zone Sud. République de Madagascar, Ministàäre de L'Energie et des Mines (MEM/SG/DG/UCP/PGRM), 839 85pp.

Gaite, B., Iglesias, A. Villaseàtor, A., Herraiz, M. \& Pacheco, J.F., 2012. Crustal structure of Mexico and surrounding regions from seismic ambient noise tomography, Geophys. J. Int., 188(3), 1413-1424.

Gilligan, A., Priestley, K.F., Roecker, S.W., Levin, V. \& Rai, S.S., 2015. The crustal structure of the western Himalayas and Tibet, J. geophys. Res., 120(5), 3946-3964.

Goutorbe, B., de Oliveira Coelho, D.L. \& Drouet, S., 2015. Rayleigh wave group velocities at periods of 6-23Â s across Brazil from ambient noise tomography, Geophys. J. Int., 203(2), 869-882.

Green, R.G., Priestley, K.F. \& White, R.S., 2017. Ambient noise tomography reveals upper crustal structure of icelandic rifts, Earth planet. Sci. Lett., 466, 20-31.

Guidarelli, M., Aoudia, A. \& Costa, G., 2017. 3-d structure of the crust and uppermost mantle at the junction between the southeastern alps and external dinarides from ambient noise tomography, Geophys. J. Int., 211, 1509-1523.

Herrmann, R. \& Ammon, C., 2004, Computer Programs in Seismology: Surface Waves, Receiver Functions and Crustal Structure, Saint Lois University.

Holbrook, W.S., Mooney, W.D. \& Christensen, N.I., 1992. The seismic velocity structure of the deep continental crust, in Continental Lower Crust, Chap. 1, pp. 1-43, eds Fountain, D.M., Arculus, R. \& Kay, R.W., Elsevier.

Hunter, J., 2007. Matplotlib: a 2D graphics environment, Comput. Sci. Eng., 9(3), 90-95.

Jöns, N. \& Schenk, V., 2008. Relics of the Mozambique ocean in the central east African Orogen: evidence from the Vohibory block of southern Madagascar, J. Metamorph. Geol., 26, 17-28.

Jöns, N. \& Schenk, V., 2011. The ultrahigh temperature granulites of southern Madagascar in a polymetamorphic context: implications for the amalgamation of the Gondwana super-continent, Eur. J. Mineral., 23(2), 127156.

Kennett, B. L.N., Engdahl, E.R. \& Buland, R., 1995. Constraints on seismic velocities in the Earth from traveltimes, Geophys. J. Int., 122(1), 108-124.

Lardeaux, J., Martelat, J., Nicollet, C., Pili, E., Rakotondrazafy, R. \& Cardon, H., 1999. Metamorphism and tectonics in southern Madagascar: an overview, Gondwana Res., 2(3), 355-362.

Legendre, C.P., Tseng, T.-L., Chen, Y.-N., Huang, T.-Y., Gung, Y.-C., Karakhanyan, A. \& Huang, B.-S., 2017. Complex deformation in the Caucasus region revealed by ambient noise seismic tomography, Tectonophysics, 712-713, 208-220.

Levshin, A. \& Ritzwoller, M., 2001. Automated detection, extraction, and measurement of regional surface waves, Pure appl. Geophys., 158, 15311545.

Lin, F.-C., Ritzwoller, M.H. \& Shapiro, N.M., 2006. Is ambient noise tomography across ocean basins possible?, Geophys. Res. Lett., 33(14).

Lobkis, O. \& Weaver, R., 2001. On the emergence of the Green's function in the correlations of a diffusive field, J. acoust. Soc. Am., 110, 3011-3017.

Luo, Y., Xu, Y. \& Yang, Y., 2012. Crustal structure beneath the Dabie Orogenic belt from ambient noise tomography, Earth planet. Sci. Lett., 313-314, 12-22.

Malcolm, A., Scales, J. \& van Tiggelen, B., 2004. Extracting the green's function from diffuse, equipartitioned waves, Phys. Rev. E, 70, 015601.

Mazzullo, A., Stutzmann, E., Montagner, J.-P., Kiselev, S., Maurya, S., Barruol, G. \& Sigloch, K., 2017. Anisotropic tomography around 
La Réunion island from Rayleigh waves, J. geophys. Res., 122(11), 9132-9148.

Nicollet, C., 1990. Crustal evolution of the granulites of Madagascar, in Granulites and Crustal Evolution, pp. 291-310, eds Vielzeuf, D. \& Vidal, P.H., Springer Netherlands.

Nougier, J., Cantagrel, J. \& Karche, J., 1986. The comores archipelago in the western Indian Ocean: volcanology, geochronology and geodynamic setting, J. Afr. Earth Sci., 5, 135-144.

Ojo, A.O., Ni, S. \& Li, Z., 2017. Crustal radial anisotropy beneath Cameroon from ambient noise tomography, Tectonophysics, 696-697, 37-51.

Paul, J.D. \& Eakin, C.M., 2017. Mantle upwelling beneath Madagascar: evidence from receiver function analysis and shear wave splitting, J. Seismol., 21(4), 825-836.

Piqué, A., 1999a. The geological evolution of Madagascar: an introduction, J. Afr. Earth Sci., 28, 919-930.

Piqué, A., 1999b. The initiation and development of the Morondava Basin (Madagascar) from the late carboniferous to the middle Jurassic: sedimentary, palaeontological and structural data, J. Afr. Earth Sci., 28, 931-948.

Pratt, M.J. et al., 2017. Shear velocity structure of the crust and upper mantle of Madagascar derived from surface wave tomography, Earth planet. Sci. Lett., 458, 405-417.

Rabinowitz, P.D., Coffin, M.F. \& Falvey, D., 1983. The separation of Madagascar and Africa, Science, 220(4592), 67-69.

Rakotondraompiana, S., Albouy, Y. \& Piqué, A., 1999. Modàäle de lithosphàäre pour l'ile de madagascar (océan indien occidental): nouvelle interprétation des don- nées gravimétriques, J. Afr. Earth Sci, 28, 961-973.

Reiss, M.C., Rümpker, G., Tilmann, F., Yuan, X., Giese, J. \& Rindraharisaona, E.J., 2016. Seismic anisotropy of the lithosphere and asthenosphere beneath southern Madagascar from teleseismic shear wave splitting analysis and waveform modeling, J. geophys. Res., 121(9), 66276643.

Rindraharisaona, E.J., Guidarelli, M., Aoudia, A. \& Rambolamanana, G., 2013. Earth structure and instrumental seismicity of Madagascar: implications on the seismotectonics, Tectonophysics, 594, 165-181.

Rindraharisaona, E.J., Tilmann, F., Yuan, X., Rümpker, G., Giese, J., Rambolamanana, G. \& Barruol, G., 2017. Crustal structure of southern Madagascar from receiver functions and ambient noise correlation: implications for crustal evolution, J. geophys. Res., 122(2), 1179-1197.

Ritzwoller, M.H., Shapiro, N.M., Barmin, M.P. \& Levshin, A.L., 2002. Global surface wave diffraction tomography, J. geophys. Res., 107(B12), ESE 4-1-ESE 4-13.

Roux, P., Sabra, K., Kuperman, W. \& Roux, A., 2005. Ambient noise cross correlation in freespace: theoretical approach, J. acoust. Soc. Am., 117, $79-84$.

Schandelmeier, H., Bremer, F. \& Holl, H.-G., 2004. Kinematic evolution of the Morondava rift basin of SW Madagascar-from wrench tectonics to normal extension, J. Afr. Earth Sci., 38(4), 321-330.

Schlüter, T., 2006. Geological Atlas of Africa, 1st edn, Springer.

Shapiro, N. \& Campillo, M., 2004. Emergence of broadband Rayleigh waves from correlations of the ambient seismic noise, Geophys. Res. Lett, 31, L07614.

Shapiro, N., Campillo, M., Stehly, L. \& Ritzwoller, M., 2005. Highresolution surface wave tomography from ambient seismic noise, Science, 307, 1615-1618.

Shapiro, N.M., Ritzwoller, M.H. \& Bensen, G.D., 2006. Source location of the $26 \mathrm{sec}$ microseism from cross-correlations of ambient seismic noise, Geophys. Res. Lett., 33(18), doi:10.1029/2006GL027010.

Sieminski, A., Lévêque, J.-J. \& Debayle, E., 2004. Can finite-frequency effects be accounted for in ray theory surface wave tomography?, Geophys. Res. Lett., 31(24), doi:10.1029/2004GL021402.

Snieder, R., 2004. Extracting the green's function from the correlation of coda waves: a derivation based on stationary phase, Phys. Rev. E, 69, 046610 .
Storey, M., Mahoney, J.J., Saunders, A.D., Duncan, R.A., Kelley, S.P. \& Coffin, M.F., 1995. Timing of hot spot-related volcanism and the breakup of Madagascar and India, Science, 267(5199), 852-855.

Taylor, G., Rost, S. \& Houseman, G., 2016. Crustal imaging across the North Anatolian Fault Zone from the autocorrelation of ambient seismic noise, Geophys. Res. Lett., 43(6), 2502-2509.

Tedla, G., Van der Meijde, M., Nyblade, A. \& Van der Meer, F., 2011. A crustal thickness map of Africa derived from a global gravity field model using euler deconvolution, Geophys. J. Int., 187, 1-9.

Thomas, R. et al., 2009. Geological evolution of the Neoproterozoic Bemarivo Belt, northern Madagascar, Precamb. Res., 172(3), 279-300.

Tilmann, F., Yuan, X., Rümpker, G. \& Rindraharisaona, E., 2012. Selasoma project, Madagascar 2012-2014, doi:10.14470/MR7567431421.

Torsvik, T., Tucker, R., Ashwal, L., Eide, E., Rakotosolofo, N. \& Wit, M.D., 1998. Late cretaceous magmatism in Madagascar: palaeomagnetic evidence for a stationary Marion hotspot, Earth planet. Sci. Lett., 164, 221-232.

Tucker, R. \& Conrad, J., 2008. 40Ar/39Ar geochronology of Mesozoic and younger igneous rocks of central and northern Madagascar, in Final Report of the BGS-USGS Consortium to the Government of Madagascar, World Bank Project UK-04-0100, Chapter 7.

Tucker, R., Peters, S., Roig, J., Théveniaut, H. \& Delor, C., 2012. Notice explicative des cartes géologique et métallogéniques de la République de Madagascar à 1/1000000, Ministère des Mines, PGRM, Antananarivo, République de Madagascar.

Tucker, R.D., Roig, J.-Y., Delor, C., Amelin, Y., Goncalves, P., Rabarimanana, M.H., Ralison, A.V. \& Belcher, R.W., 2011. Neoproterozoic extension in the Greater Dharwar Craton: a reevaluation of the Betsimisaraka "suture" in Madagascar, Can. J. Earth Sci., 48(2), 389-417.

Tugume, F., Nyblade, A., Julià, J. \& van de Meijde, M., 2013. Precambrian crustal structure in Africa and Arabia: evidence lacking for secular variation, Tectonophysics, 609, 250-266.

Wapenaar, K., 2004. Retrieving the elastodynamic green's function of an arbitrary inhomogeneous medium by cross correlation, Phys. Rev. Lett., 93, 254301 .

Weaver, R. \& Lobkis, O., 2004. Diffuse fields in open systems and the emergence of the green's function, J. acoust. Soc. Am., 116, 2731-2734.

Webb, S.C. \& Crawford, W.C., 1999. Long-period seafloor seismology and deformation under ocean waves, Bull. seism. Soc. Am., 89(6), $1535-1542$.

Wessel, P. \& Smith, W., 1998. New, improved version of generic mapping tools released, EOS, Trans. Am. geophys. Un., 79, 579.

Wysession, M., Wiens, D. \& Nyblade, A., 2011. Investigation of sources of intraplate volcanism using Passcal broadband instruments in Madagascar, the Comores, and Mozambique, International Federation of Digital Seismograph Networks. Dataset/Seismic Network, doi:10.7914/SN/XV_2011.

Yang, Y., Ritzwoller, M., Levshin, A. \& Shapiro, N., 2007. Ambient noise Rayleigh Wavet Omography across Europe, Geophys. J. Int., 168, 259274.

Yoshizawa, K. \& Kennett, B.L.N., 2002. Determination of the influence zone for surface wave paths, Geophys. J. Int., 149(2), 440-453.

Young, M.K., Rawlinson, N. \& Bodin, T., 2013. Transdimensional inversion of ambient seismic noise for 3D shear velocity structure of the Tasmanian crust, Geophysics, 78(3), WB49-WB62.

Yu, G.K. \& Mitchell, B.J., 1979. Regionalized shear velocity models for the pacific upper mantle from observed Love and Rayleigh wave dispersion, Geophys. J. R. astr. Soc., 57, 311-341.

Zhou, Y., Dahlen, F.A. \& Nolet, G., 2004. Three-dimensional sensitivity kernels for surface wave observables, Geophys. J. Int., 158(1), 142-168. 


\section{SUPPORTING INFORMATION}

Supplementary data are available at $G J I$ online.

Figure S1. (a) The upper panel shows Rayleigh wave group velocity dispersion curves measured for station pairs in the sedimentary basin while the lower panel shows their corresponding crosscorrelation waveforms. Panel (b) same as in (a) but for stations in the Precambrian shield.

Figure S2. Misfit is presented as reduction of variance delivered by the estimated maps relative to the predicted group velocity maps.

Figure S3. $2.5^{\circ}(\sim 250 \mathrm{~km})$ anomaly size checkerboard test for 5 , 10,20 and 30 s periods.

Figure S4. $150 \mathrm{~km}$ anomaly size checkerboard test for 5 and $10 \mathrm{~s}$ periods. $200 \mathrm{~km}$ anomaly size test for $20 \mathrm{~s}$ period.

Figure S5. 3-D Vs models at 30 and $40 \mathrm{~km}$ depths.
Figure S6. Record sections of vertical component CCFs for OBS station RR03.

Figure S7. A plot of approximately one month (July, 2013) long raw and corrected signals from the OBS station RR03 of the RHUMRUM network.

Figure S8. Same as in Fig. S7 but for OBS station RR21.

Figure S9. Calculation of SNR shown for CCF between stations BARY and RR03. SNR is the ratio of the maximum absolute amplitude in the signal window to the standard deviation in the noise window.

Please note: Oxford University Press is not responsible for the content or functionality of any supporting materials supplied by the authors. Any queries (other than missing material) should be directed to the corresponding author for the article. 